فاعلية استراتيجية التدريس التبادلي في تحصيل مادة طرائق تدريس اللغة العربية

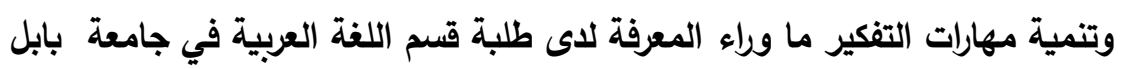

م م.د. مهاد كامل جبار

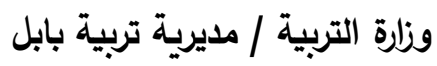

\title{
souhadkamil@gmail.com
}

الملخص

يهدف البحث إلى قياس فاعلية استراتيجية التدري التبادلي في تحصيل مادة طرائق تدريس اللغة

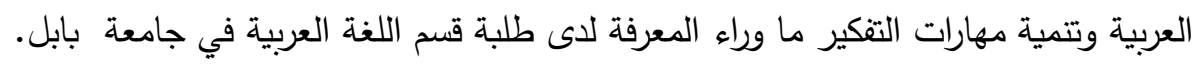
ولتحقيق البحث وضعت الفرضيتين الصفريتين التي تفترض عدم وجود فرق ذي دلالة معنوية عند مستوى (0., •) بين متوسط درجات الطلبة في المجموعتين (التجرببية والضابطة) في الاختبار البعدي لمادة طرائق تدريس اللغة العربية ومهارات التفكير ما وراء المعرفة. لين.

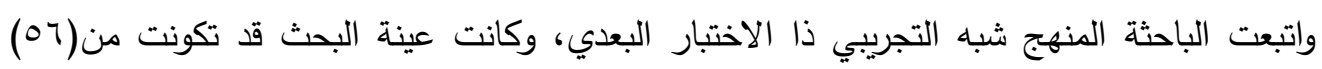

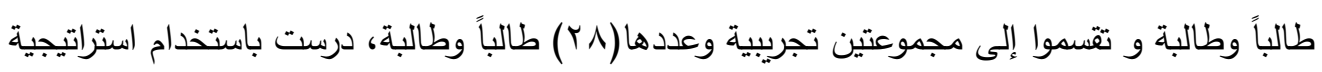
التدريس التبادلي والضابطة وعددها (Y^) طالباً وطالبة ، درست بالطريقة الاعتيادية وتمت مكافئة المجموعتين في المتغيرات الدخيلة. وأعدت الباحثة أداتا، الأولى اختبار تحصيلي تكون من ( • ع) فقرة ، والأداة الثانية هي مقياس التفكير ما وراء المعرفة والذي تكون من (Y乏) فقرة ، وتم أجراء لكلاهما الصدق والثبات والتحليل الإحصائي لفقراتهما

وكان من نتائج البحث تفوق المجموعة التجريبية التي هي باستخدام استراتيجية التدريس التبادلي على المجموعة الضابطة في التحصيل والتفكير ما وراء المعرفة . الكلمات المفتاحية: استراتيجية التدري التبادلي، ،التحصيل، التفكير ما وراء المعرفة. 
العزعد الرابع والأربعون

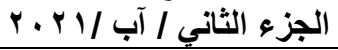

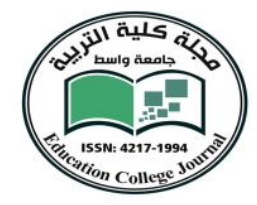

The effectiveness of the reciprocal teaching strategy in the acquisition of Arabic language teaching methods and the development of metacognitive thinking skills among the students of the Arabic language department at the University of Babylon

\begin{abstract}
The research aims to measure the effectiveness of the reciprocal teaching strategy in the acquisition of Arabic language teaching methods and the development of metacognitive thinking skills among students of the Arabic Language Department at the University of Babylon.

To achieve the goal of the research, the two null hypotheses were put in place, which assumes that there is no significant difference at the level (0.05) between the average scores of students in the two groups (experimental and control) in the post-test of Arabic language teaching methods and metacognitive thinking skills.

To achieve the goal of the research, the two nu

11 hypotheses were put in place, which assumes that there is no significant difference at the level $(0.05)$ between the average scores of students in the two groups (experimental and control) in the post-test of Arabic language teaching methods and metacognitive thinking The researcher prepared two tools, the first is an achievement test consisting of (40) items, and the second tool is the Metacognitive Thinking Scale, which consists of (42) items.

One of the results of the research was the superiority of the experimental group that used the reciprocal teaching strategy

On the control group in achievement and metacognitio
\end{abstract}

Keywords: reciprocal teaching strategy, achievement, metacognition. 


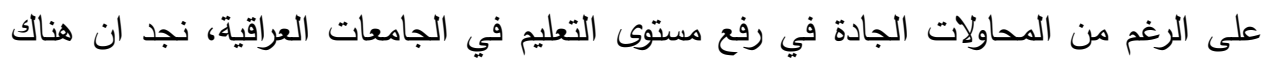
قصور الأساليب المتبعة في التدريس الجامعي حيث ان اغلب طرائق التدريس المتبعة في النظام

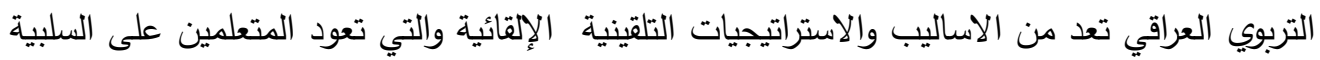

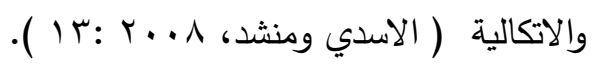

واكدت الكثير من الدراسات المحلية الى ان انخفاض مستوى التفكير بصورة عامة ل لاى الطلبة سبيه

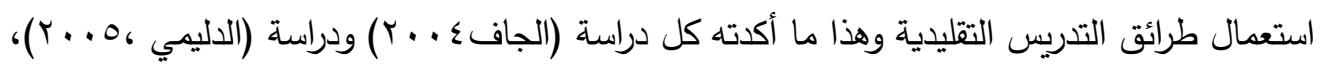

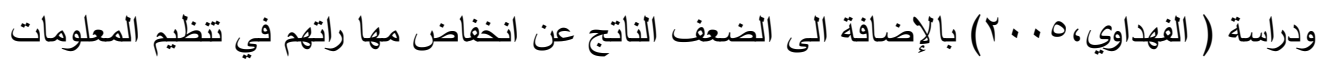

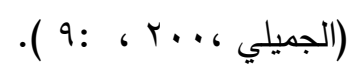

من خلال عمل الباحثة كتدريسية في جامعة بابل شعرت بان هناك ضعف لإى الطلبة في عملية

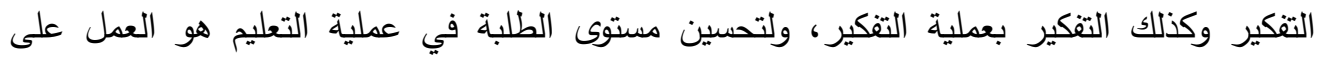

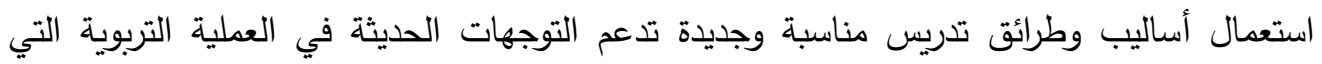
تجعل من الطالب محور العملية التعليمية، ورفع مستوى التحصيل ومهارات التقكير العليا المتمثلة

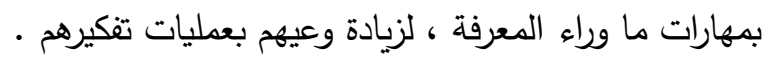

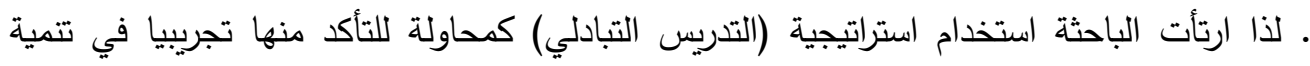

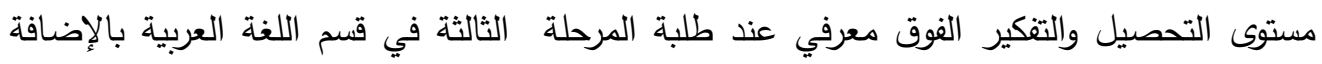

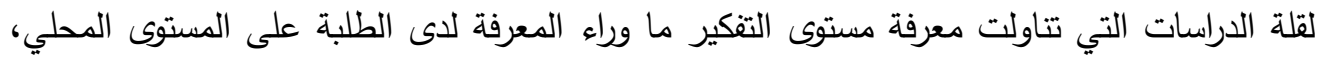

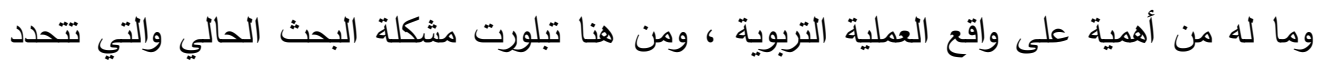

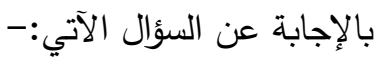
ما فاعلية استراتيجية التدريس التبادلي في تحصيل مادة طرائق تدريس اللغة العربية وتتمية مهارات

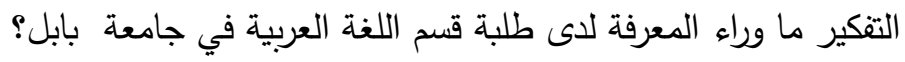




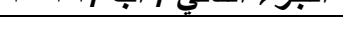

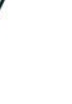

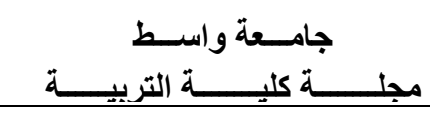

أهمية البحث:

تتمثل أهمية الدراسة فيما ياتي:- البحث:

ا - أهمية مادة طرائق تدريس اللغة العربية لطلبة الجامعة. ז- تتاولها التفكير ما وراء المعرفي لدى الطلبة لجعلهم قادرين على التعامل مع المواقف الجديدة بنجاح ، وتجعلهم متعلمين ومفكرين. "- كونها تنسجم مع التوجهات الحديثة في مجال التدريس والتي تجعل المتعلم محور العملية التدريسية وتهتم بتتمية التفكير ما وراء المعرفة لدى طلبة الجامعة. ـ - أهمية طلبة الجامعة الذين يشكلون العصب الرئيس في عملية التطوير والتحديث ويشكلون رأسمال الثروة الوطنية . هـ تمثل هذه الدراسة بنتائجها اضافة جديدة في الميدان التربوي واستجابة لضرورة اعادة النظر في طرائق التدريس التقليدية واعتماد الطرائق والاستراتيجيات التدريسية الحديثة ومنها استراتيجية ( التدريس

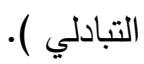
ج- قد تفتح هذه الدراسة المجال أمام دراسات أخرى مشابهة باستخدام استراتيجيات جديدة في تتمية ما وراء المعرفة . V- ق قد تساعد هذا الدراسة في توجيه نظر المسؤولين في التعليم الجامعي إلى ضرورة الاهتمام بتقديم دورات تدريبية تسهم في تحسين الأداء التدريسي. هدفا البحث

$$
\text { يهدف البحث الحالية الى:- }
$$

الهرف الأول : التعرف فاعلية استراتيجية التدريس التبادلي في تحصيل مادة طرائق تدريس اللغة العربية وتتمية مهارات التفكير ما وراء المعرفة لدى طلبة قسم اللغة العربية في كلية التربية الأساسية

جامعة بابل ولتحقيق هذا الهدف سيتم اختبار الفرضيات الصفرية مقابل فرضياتها البديلة:" لا توجد فروق ذات دلالة إحصائية بين متوسط درجات القياس البعدي لأفراد المجموعة التجريبية التي درست باستراتيجية التدريس التبادلي، ومتوسط درجات القياس البعدي للمجموعة الضابطة التي درست بالطريقة التقليدية وبمستوى دلالة (0. . • ) على الاختبار التحصيلي لمادة طرائق تدريس اللغة 
الهدف الثاني : التعرف على فاعلية استراتيجية التدريس التبادلي في تتمية مهارات التفكير ما وراء المعرفة لاى مجموعتي البحث ( التجريبية والضابطة).. ولتحقيق هذا الهدف سيتم اختبار الفرضيات الصفرية مقابل فرضياتها البديلة: الفرض الأول "لاتوجد فروق ذات دلالة إحصائية بين درجات القياسات القبلية والبعدية لأفراد المجموعتين التجريبية والضابطة، وبمستوى دلالة (0 . . ·على مقياس مهارات التفكير ماوراء المعرفة. الفرض الثاني" لا توجد فروق ذات دلالة إحصائية بين درجات القياسات القبلية والبعدية لأفراد

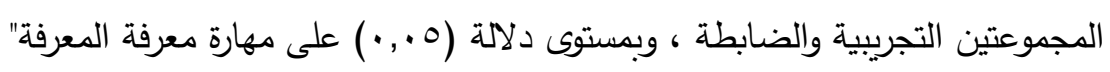
الفرض الثالث" لا توجد فروق ذات دلالة إحصائية بين درجات القياسات القبلية والبعدية ، وبمستوى دلئه

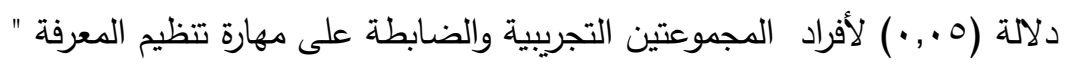

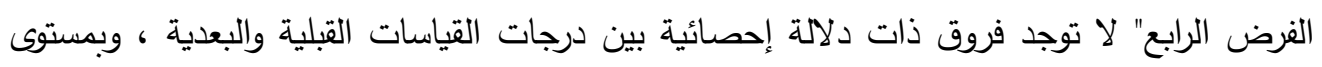
دلالة (0. . • ) لأفراد المجموعتين التجريبية والضابطة على مهارة معالجة المعرفة حدود الدراسة اقتصرت الدراسة الحالية على عينة من طلبة المرحلة الثالثة، قسم اللغة العربية، كلية التربية الأساسية

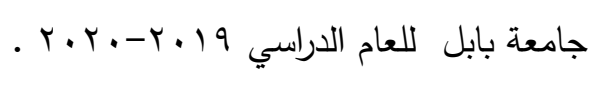
مصطلحات البحث تعتمد الدراسة التعريفات الآتية لمصطلحاتها: ا - استراتيجية التدريس التبادلي: وهي عبارة عن استراتيجية في التدريس يتم فيها إدارة حوار بين المعلم والطلاب، أو بين الطلاب مع مع بعضهم بعضاً، بحيث يتبادلون مجموعة من الأنشطة التعليمية والأدوار طبقاً لعناصر التدريس التبادلي الفرعية، وهي: التتبؤ، والتوضيح، والتساؤل، والتصور الذهني، والتلخيص، من أجل فهم المادة

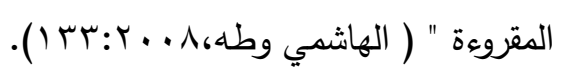

ץ - مهارات التفكير ما وراء المعرفة : هي التفكير في التفكير والوعي به وقدرة المتعلم على معرفة المعرفة، وتتظيمها، ومعالجتها، ويقاس من خلال إجابات الطلبة على مقياس التفكير ما وراء المعرفي

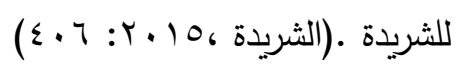
r- التحصيل : درجة اكتساب الطالب التي يحققها الفرد، أو مستوى النجاح الذي يحرزه أو يصل إليه في مادة دراسية أو مجال تعليمي أو تدريسي معين ،ويقاس بالاختبار التحصيلي الذي اعدته الباحثة. 


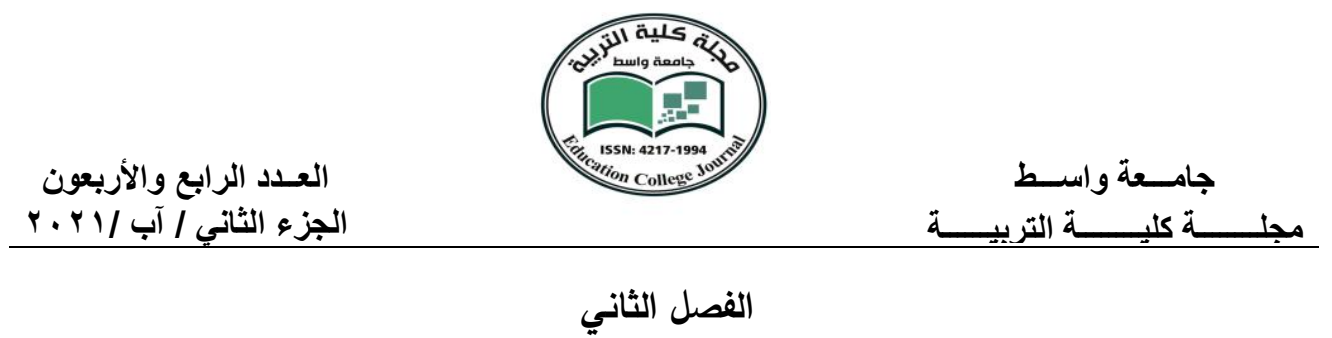

الخلفية النظرية والدارات السابقة

تناولت الباحثة في بحثها الحالي محورين هما: إستراتيجية التتريس التبادلي و التفكير ما وراء المعرفي: عناصر استراتيجية التربيس التبادلي: ويقوم التدريس التبادلي بضم العديدمن الاستراتيجيات تساعدالمتعلم على الفهم وتتمية القدرات العقلية العليا من طريق تطبيق الخطوات للتدريس التبادلي كما هي موضحة ، وهي : (التنبؤ - التساؤل التوضيح - التصور الذهني - التلخيص ).

Predicting التنبؤ

تتطلب هذه المرحلة من الطالب أن يتنبأ ما قد تعلم او قرا من النص ،مما يشكل هدفًا أمام

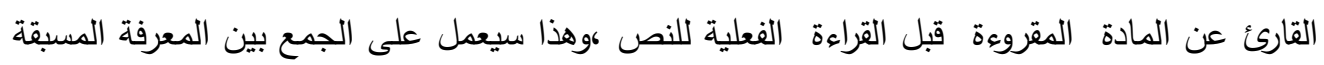
للقارئ، مع معارف جديدة من النص، وبنية النص ، ويوفر التتبؤ الأساس المنطقي العام للقراءة-

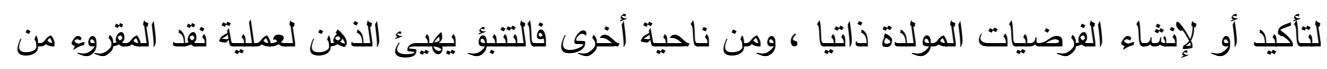

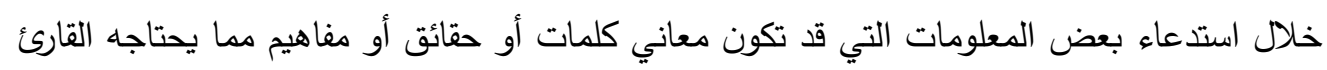
لتتييم المادة المقروءة واصدار حكم ، الأمر الذي يوفر هدف أمام الطالب ويضمن التركيز في أثناء

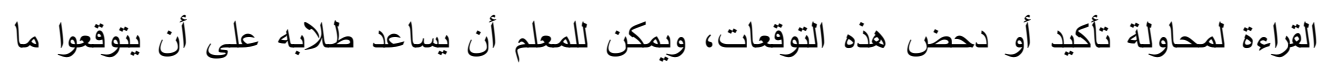

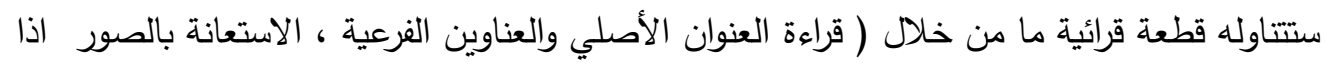

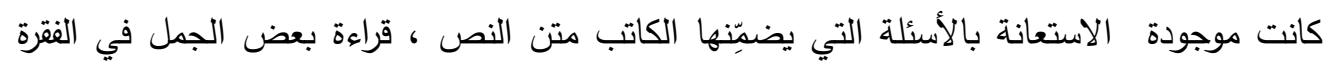

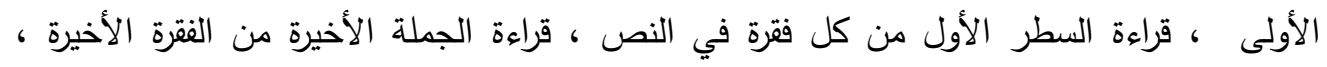

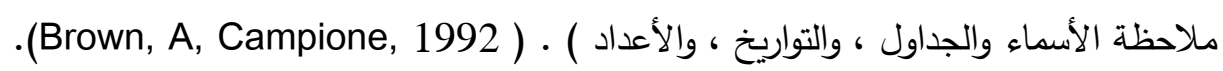

r Summarizing التلخيص

هي عملية تحديد المعلومات الهامة، والمواضيع، والأفكار داخل النص المقروء واحداث تكامل بين

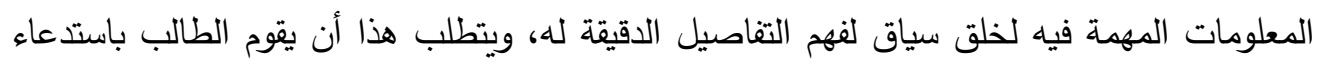

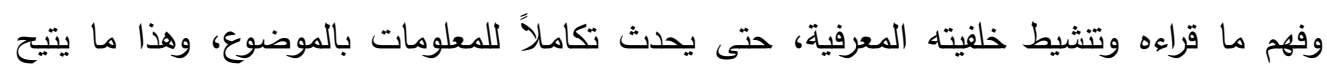

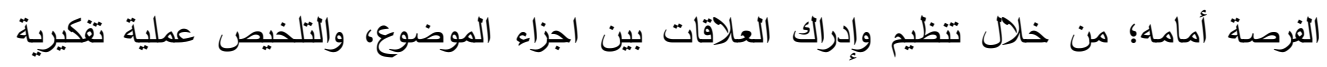
تتضمن القدرة على إيجاد لب الموضوع واستخراج الأفكار الرئيسية منه، والتعبير عنها لبإيجاز

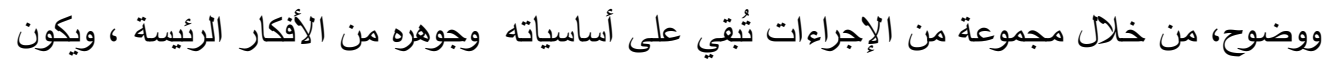


دور المعلم في هذه الاستراتيجية بالتأكيد على ضرورة استخدام كلمات الطلاب الخاصة ، وليس

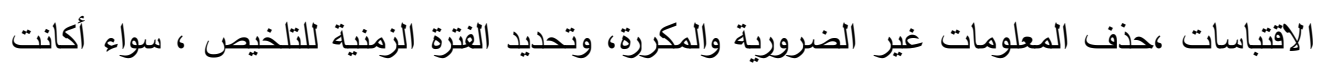

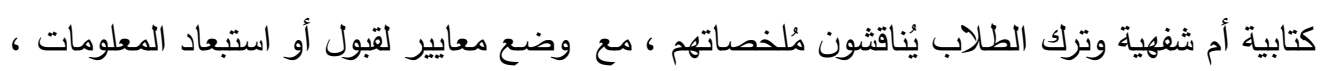

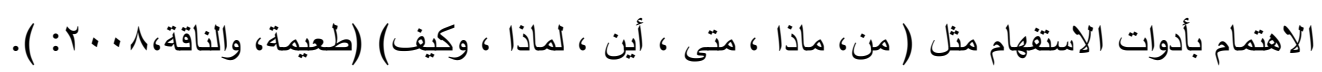

\section{بuestioning التساؤل}

في استخدام استراتيجية التساؤل يتم رصد وتقييم المعلومات والمواضيع والأفكار الخاصة، مدا ها يوفر سياقاً لاستكثاف النص الأكثر عمقاً، وفي هذه المرحلة يتم توجيه الطلاب إلى طرح أسئلة عديدة

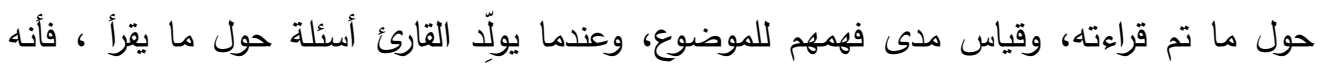

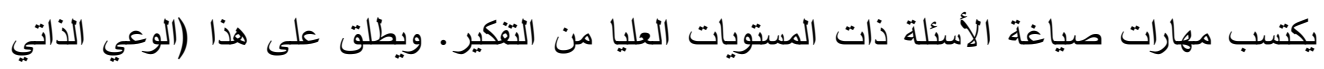

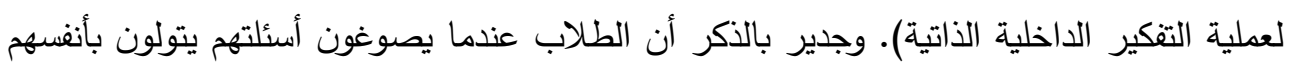

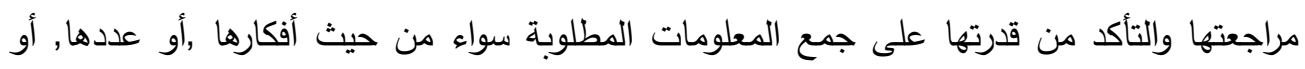
صياغتها , صراغنا ولتان وتوليد الأسئلة هنا عملية مرنة ترتبط بالهدف الذى يتوخاه المعلم ,أو المنهج والمهارات المطلوب تتميتها وهنا يجب على المعلم أن يساعد طلابه على توليد مجموعة من الأسئلة الجيدة حول أهم الأفكار

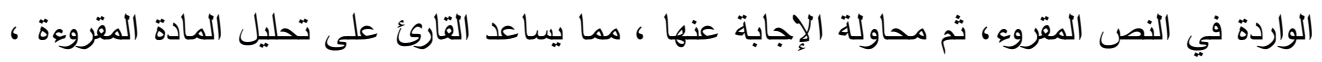

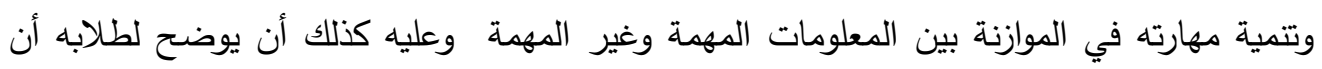

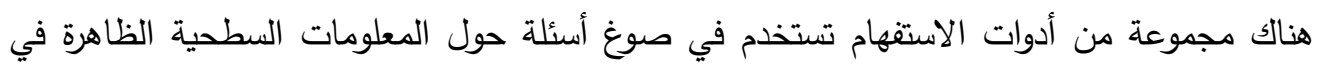

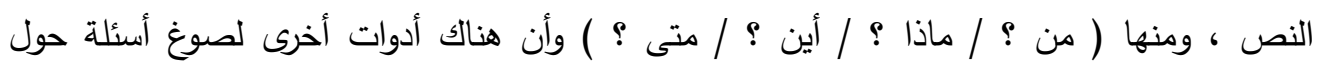

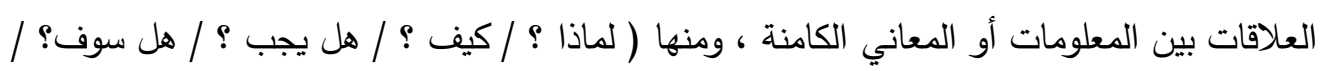

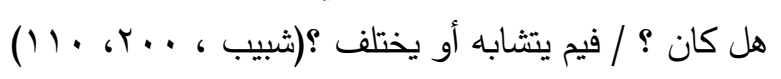

\section{ع - التصور الذهني}

في هذه المرحلة يقوم القارئ بالتعبير عن انطباعاته الذهنية حول المحتوى المقروء من خلال

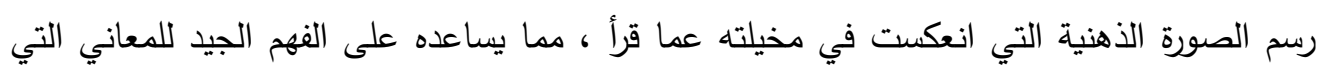
تعبرعنها الألفاظ المستخدمة في النص المقروء، وهنا يجب أن يبين المعلم لطلابه أنه عندما يقرأ

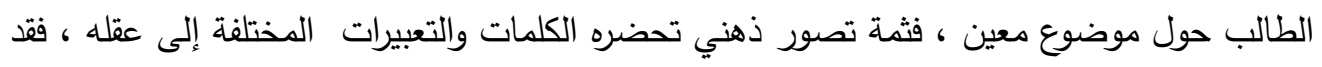
يرى أثياء أو يسمع أصواتًا تبعثها الكلمات وتعكسها الأحداث ليرسم صورة دمنئ عن انطباعه عما قراً ، 
مما يساعده في فهمه ، ومن ثم بعد ذلك يصوغ المعلم بعضًا من الأسئلة حول الفقرة المعروضة ، ثم يلفت نظر طلابه للتفكير بصوت مرتفع وتوضيح كيفية انتقاء المعلومات وكيفية صياغتها بشكل جيد

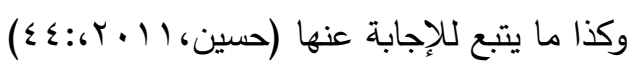

\section{: Clarifying التوضيح}

تركز إستراتيجية التوضيح على تدريب الطلاب في خطوات محددة للمساعدة في فك التشفير

(التدقيق الإملاتئي، وما إلى ذلك)، فضلا عن ذلك ان التوضيح ينطوي على تحديد وتوضيح جوانب غير واضحة أو صعبة أو غير مألوفة للنص. وهذه المرحلة تاتي لتحديد ما صعب على الطلاب من كلمات أو جمل قد تعترضهم مما تمثل عائقًا في فهم المعلومات المتضمنة بالمقروء سواء كلمات أم مفاهيم أم تعبيرات أم أفكار، مما يساعد القارئ على اكتشاف قدرة الكاتب على استخدام الألفاظ والأساليب في التعبير عن المعاني ، والاستعانة بمساعدات من داخل القطعة أو خارجها للتغلب على لهى هذه الصعوبات، وفي هذه المرحلة أن الطلاب يقومون بالاستفسار عن المفاهيم والمصطلحات الصعبة أو غير المألوفة في النص، ويتم ذلك من خلال شرح الأسس التي استند عليها، وعمليات الملاحظة، والتصنيف، والمقارنة، ومناقشات المعلم وتوجيههم إلى الإجابات مثل( الاستعانة بالسياق

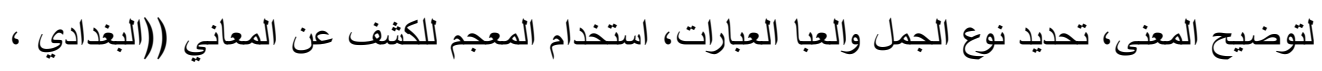

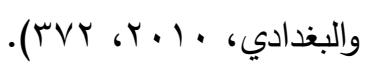

أن خطوات إستراتيجية التدريس التبادلي ليس بالضرورة أن ترتب على وفق ترتيب معين ,وإنمأ يمكن أن تسبق خطوة خطوة أخرى ، وذلك بحسب مأ يتطلبه الموقف التعليمي ، وطبيعة المادة الدراسية بين بين

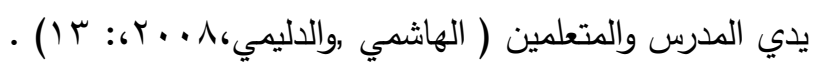
المحور الثاني : التفكير ما وراء المعرفة: Metacognition أساسيات التفكير فوق المعرفي : يتضمن التفكير فوق المعرفي مجموعة ومهارات ينبغي أن يتعلهها المتعلم مما يساهم في زيادة عاداته العقلية من خلال فهم العمليات والمهارات التعليمية بالإضافة إلي التحكم في جميع عمليات التعلم من حيث تحديد الأهداف والتظظيم والتتسيق الذاتي الواعي والتقييم والنقد البناء ،وأن معظم العلماء أجمعوا على أن التفكير فوق المعرفي يتضمن ما يلي: ا- المعرفة عن المعرفة: وتتضمن معرفة المتعلم لطبيعة التعلم والتعليم وعملياته وأغراضه ومعرفة

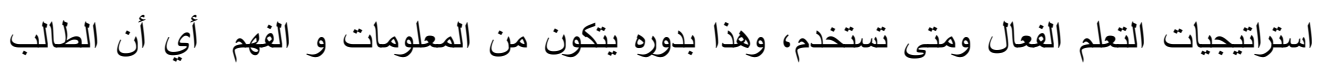
يجب أن يفهم عمليات التفكير خاصة العمليات التي يستخدمها بذاته في التعلم، وكذلك يجب أن تكون 
لاي الطالب المعلومات الكافية عن استراتيجيات التعلم المختلفة حتى يختار أنسبها بالنسبة له ليستخدمها في المواقف التعليمية التي يمر بها. r - تنظيم المعرفة: ويشير إلي مدي وعي المتعلم بالإجراءات التي ينبغي القيام بها لتحقيق نتيجة معينه ويتضمن ثلاثة أبعاد هي الوعي بمتغيرات الثخصية والوعي بمتغيرات الموقف التعليمي والوعي بمتغيرات الإستراتيجية الملائمة r- - معالجة المعرفة: وتعبر عن طبيعة القرارات الواعية التي يتخذها المتعلم بناءاً علي معرفته

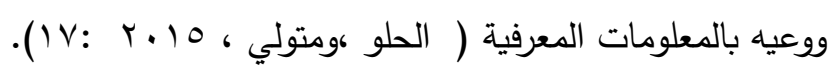
الاراسات السابقة:

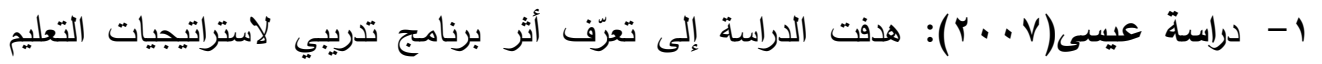
التبادلي على ما وراء الفهم لدى الطلاب ذوي صعوبات الفهم القرائي في الصف الخامس الابتدائي. وتكونت عينة الدراسة من 79 طالباً من الذكور ذوي صعوبات الفهم القرائي وجميعهم من تلاميذ الصف الخامس الابتدائي بمدرسة الوليدية الابتدائية الجديدة المشتركة بأسيوط، في العام الدراسي دوبي

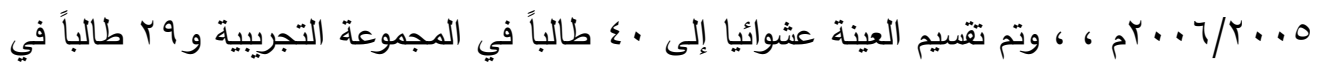
المجموعة الضابطة. وتم تطبيق اختبار الفهم القرائي واختبار التعرف القرائي ومقياس ستانفورد - بينيه للذكاء ومقياس ما وراء الفهم والبرنامج التدريبي لاستراتيجيات التعليم التبادلي، وتم التدريب على ولى البرنامج خلال ثلاثة عشر جلسة بمعدل ثلاث جلسات أسبوعياً، ولمعالجة النتائج والتحقق من صحة ولتئي الفروض تم استخدام اختبار ت لالالة فروق متوسطات درجات الكسب. وتوصلت الدراسة إلى تحسن مستوى ما وراء الفهم وكذلك الفهم القرائي لدى الطلاب ذوي صعوبات الفهم القرائي في المجموعة التجريبية ولم يظهر هذا التحسن لاى نظرائهم في المجموعة الضابطة.

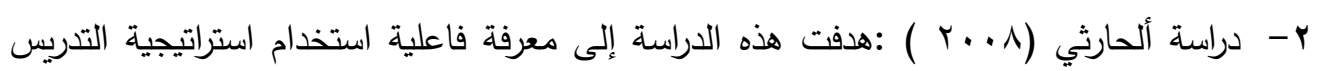
التبادلي في تتمية مهارات ما وراء المعرفة في القراءة" التخطيط للقراءة ، المراقبة والتحكم في القراءة ، وتقويم القراءة "منفصلة ومجتمعة، في مادة القراءة لدى طلاب المرحلة الثانوية ،وقد تم اختبار تلك الفروض عن طريق إجراء دراسة شبه تجريبية على عينة مختارة عشوائيا من مجتمع الدراسة ، حيث شمل طلاب الصف الثاني الثانوي شرعي في ثانوية جرير بمحافظة جدة وتكونت عينة الدراسة من

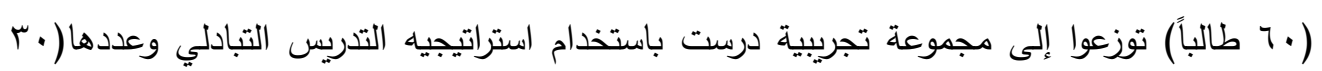
طالباً) وضابطة (• ط طالباً) درست باستخدام الطريقة التقليدية، كما قام بإعداد اختبار تحصيلي تأكد 
من صدقه وثباته، وتم تطبيقه على الدوعتين التجريبية والضابطة (قبليا وبعدياً، وباستخدام تحليل التباين المصاحب كأسلوب إحصائي، تم التوصل إلى النتائج التالية :

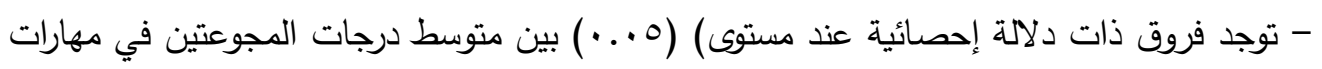

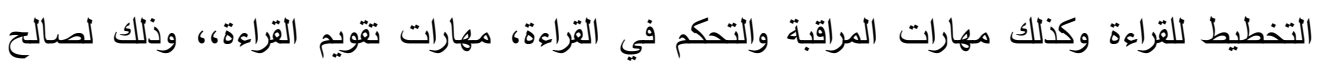
التجريبية وكان مما أوصت به الدراسة ما يلي:

- يفضل أن يستخدم معلمو مادة القراءة ومواد اللغة العربية خصوصاً، والمعلمون عموما إستراتيجية التدريس التبادلي والتأكيد على أهميتها.

r- دراسة البهادلي (11) ب (1) ترمي هذه الدراسة إلى معرفة أثر استراتيجية التدريس التبادلي في

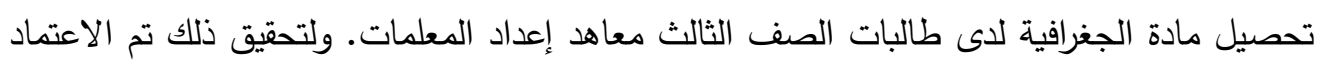

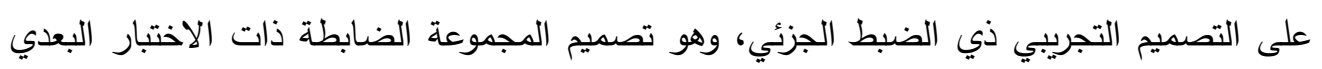

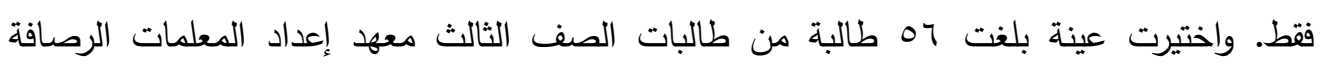

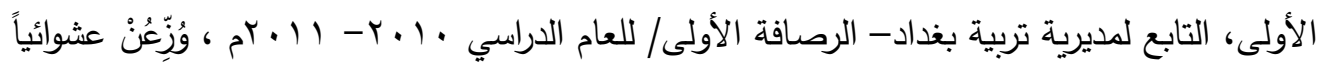

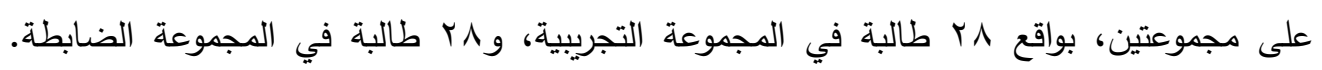

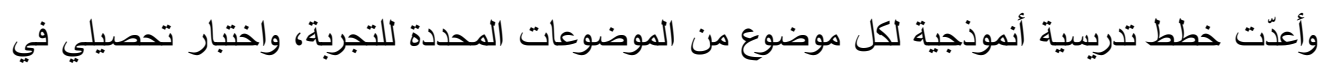
أربعة أسئلة. وظهر فرق ذو دلالة إحصائية بين تحصيل طالبات مجموعتي الدراسة ولمصلحة الدئة

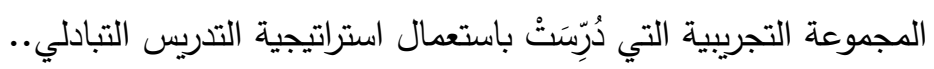
ما أفادت الدراسة الحالية من الدراسات السابقة: - بناء الإطار النظري، والاستفادة منه في اختيار مقياس التفكير ما وراء المعرفة.. - اختبار الأساليب الإحصائية . - تفسير النتائج التي توصلت إليها الدراسة بالاستفادة من الدراسات السابقة . 
الفصل الثالث

منهجية البحث وإجراء اته

يتضمن هذا الفصل عرض للإجراءات المتبعة في هذا البحث التي تضم اختيار التصميم التجريبي ، وتحديد مجتمع البحث وعينته ، والسلامة الداخلية والخارجية للتصميم وإجراءات تطبيق التجربة ، وتحديد المادة العلمية وصياغة الأهداف السلوكية ، وإعداد الخطط التدريسية للتجربة وبناء الاختبار

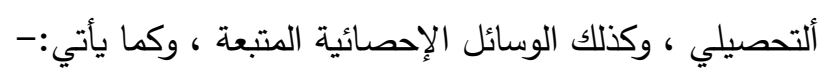
اولا : التصميم التجريبي: اتبعت الباحثة المنهج التجريبي ذي الضبط الجزئي لملائمته لظروف بحثها

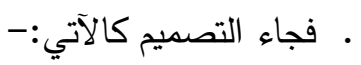

\begin{tabular}{|c|c|c|c|c|}
\hline الاختبار البعدي & المتغير التابع & المتغير المستقل & الاختبار آلقبلي & المجموعات \\
\hline \multirow{2}{*}{ مقياس مهارات التفكير } & التحصيل الدراسي & استراتيجية التدريس & \multirow{2}{*}{ المجموعات } & التجريبية \\
\hline & تنتمية مهارات التفكير & الطريقة التقليدية & & الضابطة \\
\hline
\end{tabular}

$$
\text { مخطط (1) التصميم التجريبي لمتغيرات البحث }
$$

ثانيا : مجتمع البحث وعينته : Population \& Sample of Research أ- مجتمع البحث: يتألف مجتمع البحث الحالي من طلبة المرحلة الرابعة في كلية التربية الاساسية

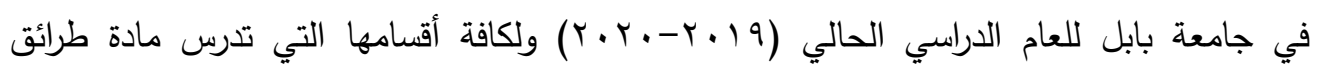

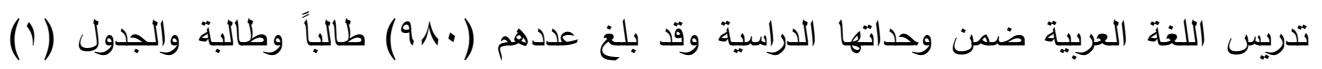
يوضتح ذلك.

$$
\text { جدول (1) مجتمع البحث }
$$

\begin{tabular}{|c|c|c|c|c|}
\hline المجموع & عدد الإناث & عدد الأكور & القسم & ت \\
\hline 71 & 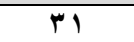 & $r$ & التربية الخاصة & 1 \\
\hline IVY & $1 \leq 0$ & YV & اللغة العربية & $r$ \\
\hline YYI & $\operatorname{lv\Lambda }$ & $\varepsilon r$ & اللغة الانكليزية & $r$ \\
\hline IVT & $11 \%$ & 7. & التاريخ & 0 \\
\hline $1 V \varepsilon$ & $11 \%$ & 71 & الجغرافية & 7 \\
\hline$\Lambda \cdot 1$ & YAY & rqA & المجموع الكلي & \\
\hline
\end{tabular}


تم اختيار طلبة المرحلة الثالثة في قسم اللغة العربية من كلية التربية الأساسية في جامعة بابل وبشكل قصدي ،وكان يضم (آ) طالبا وطالبة موزعين على شعبتين ، وبعد استبعاد (0) من

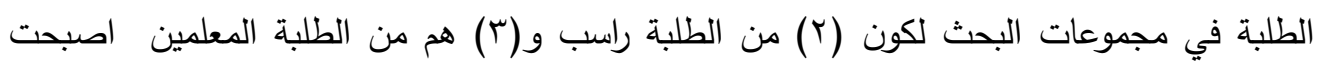
العينة متكونه من (70) طالب وطالبة ، موزعين على مجموعتين تم تحديدهما بشكل عشوائي لتكون شعبة (ب،^^) طالب وطالبة وتمثل المجموعة التجريبية والتي تدرس باستراتيجية التدريس التبادلي

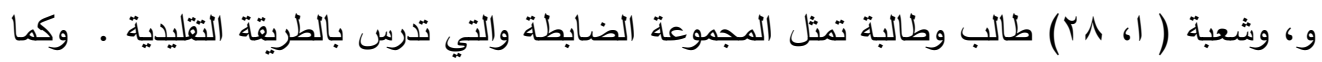
موضتح في الجدول (r) مونه جدول (r) توزيع افراد عينة البحث على المجموعات

\begin{tabular}{|c|c|c|c|}
\hline عدد الطلبة بعد & عدد الطلبة قبل الاستبعاد & الشعب & المجموعات \\
\hline$r \wedge$ & 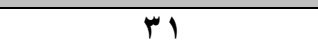 & ب & التجريبية \\
\hline$r \wedge$ & $\mu$. & 1 & الضابطة \\
\hline 09 & 71 & & المجموع \\
\hline
\end{tabular}

ثالثا : اجراءات الضبط: أ- السلامة الداخلية: لأجل التأكد من السلامة الداخلية للبحث الحالي عمدت الباحثة الى مكافئة مجاميع البحث في بعض المتغيرات التي قد تؤثر على نتائج التجربة الحالية، وذلك من اجل توفير درجة مقبولة من الصدق الداخلي، وفي ضوع ذلك قامت الباحثة بضبط المتغيرات الاتية:-

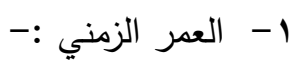

حصلت الباحثة على أعمار طلبة مجموعتي الدراسة (الضابطة والتجريبية ) من خلال قسم التسجيل في الكلية ، وقد تراوحت أعمار المجموعتين بين ( ب (Y-M) سنة ، وهذا يعني أن مجموعتي البحث متكافئتان في العمر الزمني. r - اختبار الذكاء:- وللتحقق من تكافؤ طلبة البحث في متغير الذكاء، تم اعتماد اختبار ( رافن )

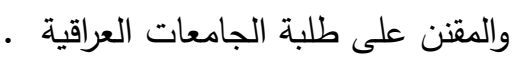
r- مهارات التفكير فوق المعرفي:- طبقت الباحثة مقياس مهارات التفكير فوق المعرفية على طلبة المجموعتين التجرببية والضابطة. 
لتحقيق السلامة الخارجية للتصميم التجريبي من خلال القيام بالإجراءات الاتية :

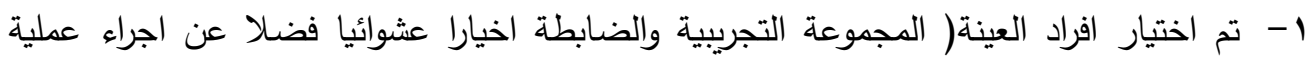
التكافؤ الاحصائي بينها في المتغيرات ( العمر الزمني ، درجة الذكاء ، القياس القبلي للتغكير ما وراء المعرفية).

ץ- تقوم الباحثة بتدريس مجموعتي البحث ( التجريبية والضابطة ) بنفسها طيلة مدة التجربة تجنبا للاختلاف الذي قد يحدث من السمات الشخصية وتأثير ذلك على مجموعتي البحث التجريبية .

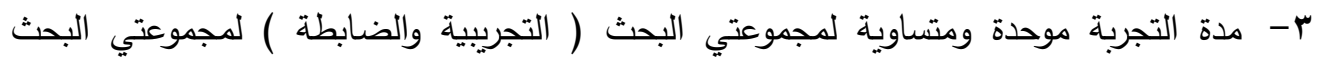
(التجريبية والضابطة).

צ - تم تدريس نفس المادة التعليمية من المادة المقررة من مفردات مادة طرائق تدريس اللغة العربية .

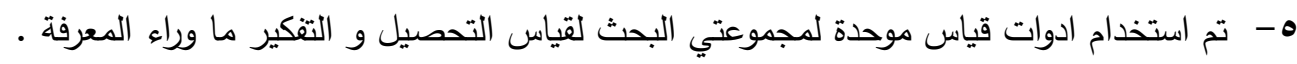

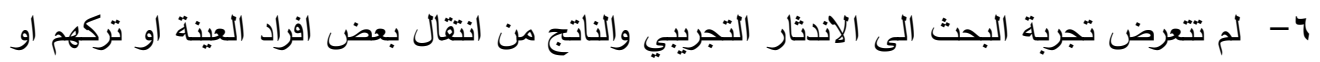
انقطاعهم عن الدوام طيلة فترة التجربة .

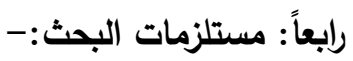
أ- تحديد المادة العلمية: حددت المادة العلمية التي ستدرسها الباحثة لأفراد عينة البحث ( التجريبية

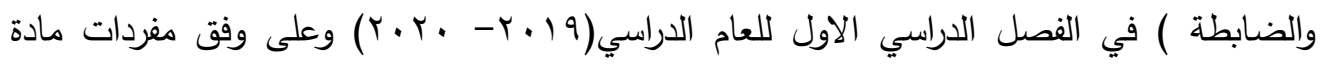

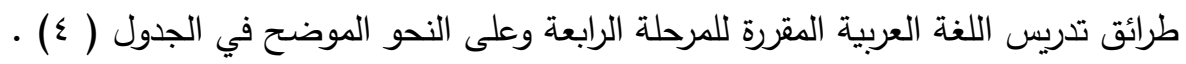

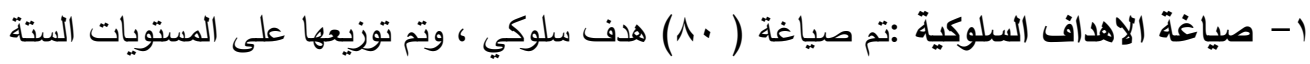

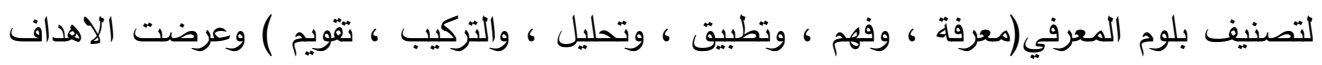

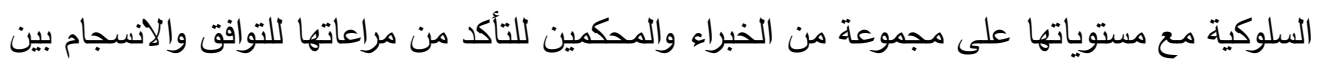

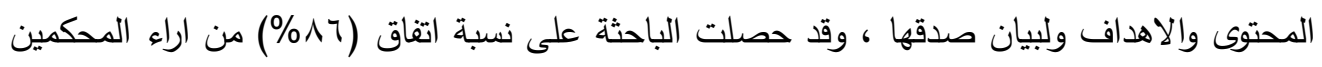

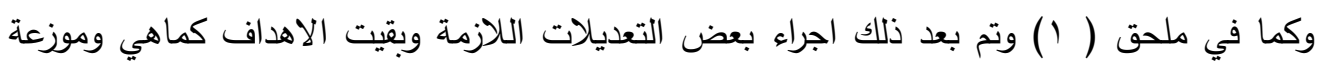

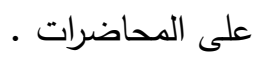

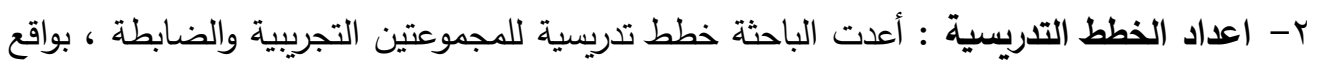
(r (1) خطة لكل مجموعة ، وبحسب الاهداف السلوكية ومحتوى المادة الدراسية واستراتيجيات التدريس

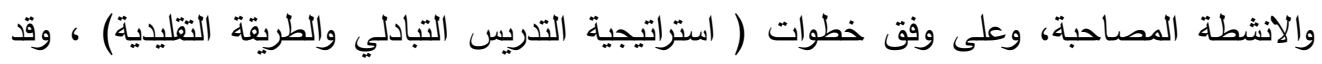
عرضت الباحثة نماذج من هذه الخطط على مجموعة من الخبراء والمحكمين المتخصصين المناهج 
وطرائق التدريس وعلم النفس التربوي (ملحق r، r ) لاستطلاع آرائهم وملاحظاتهم لتعديل صياغة تلك الخطط ،وفي ضوء ملاحظاتهم وآرائهم تم اجراء بعض التعديلات على الخطط وأصبحت جاهزة • للتطبيق

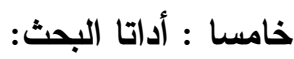
من متطلبات البحث الحالي توفير أداتين لقياس المتغيرين التابعين ،الأول اختبار تحصلي في مادة طرائق تدريس اللغة العربية ، والثاني مقياس التنكير ما وراء المعرفة وفيما يلي عرضا للإجراءات التيني وكما يلي: اولاً: الاختبار ألتحصيلي: لما كان البحث الحالي يتطلب إعداد اختبار تحصيلي بعدي لطلبة

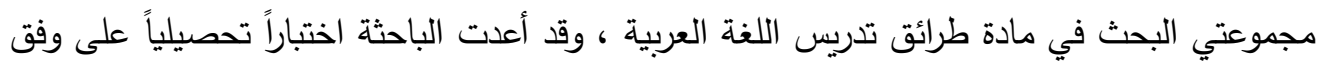
الخطوات الآتية :

1- تحديد الهاف من الاختبار : يهدف الاختبار التحصيلي إلى قياس تحصيل طلبة المرحلة

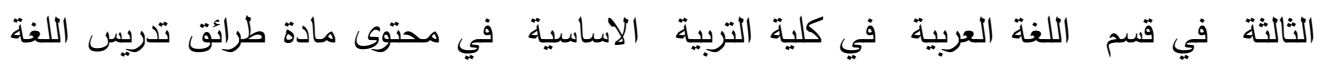

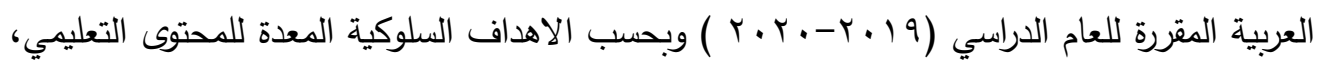

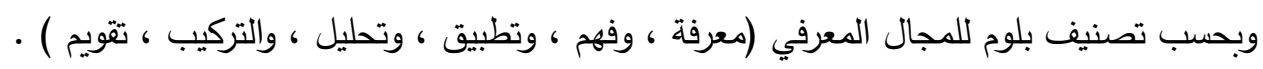
ץ - اعداد فقرات الاختبار وتعليماته:

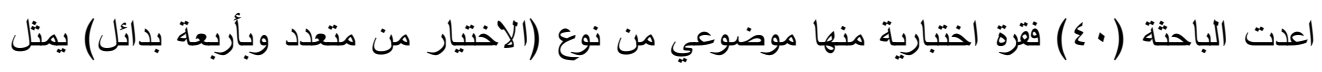

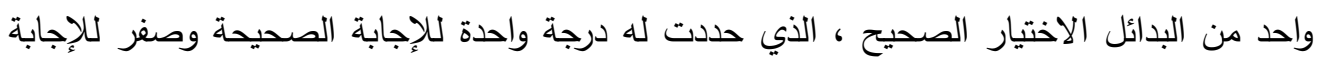

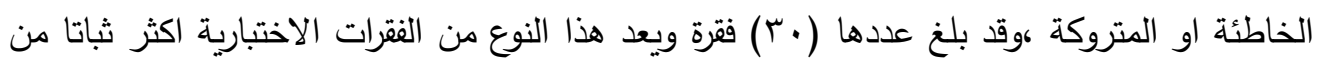

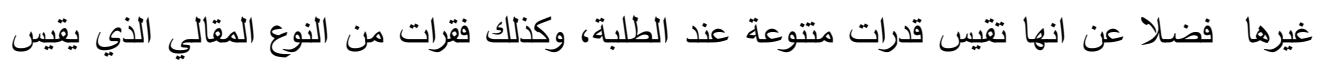

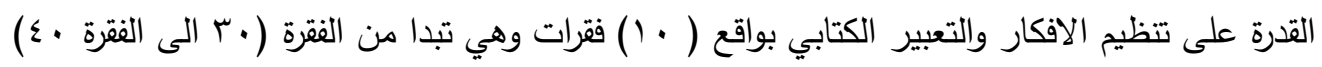

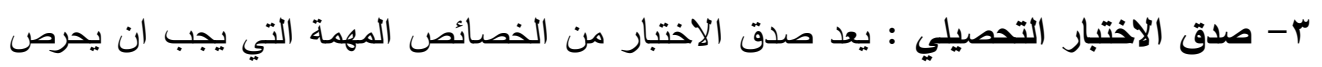

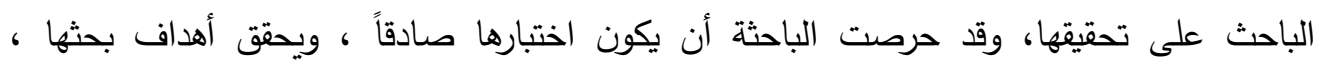

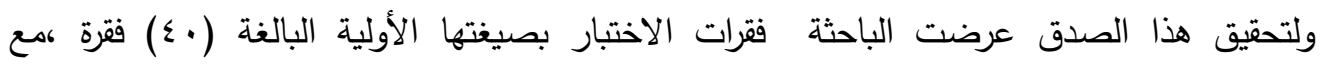

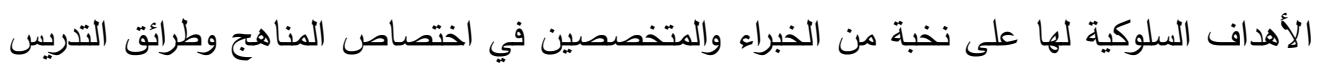

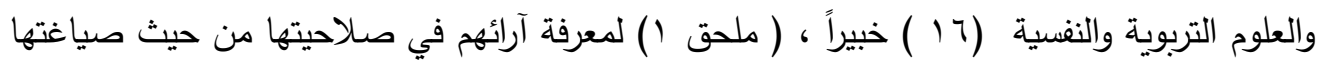

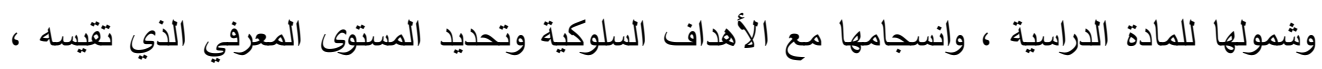

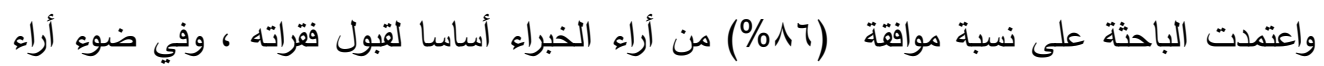


الخبراء وملاحظاتهم أعيدت صياغة عدد من الفقرات وبهذا بقيت عدد فقرات الاختبار بصيغته النهائية

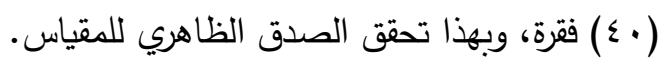
צ - التطبيق الاستطلاعي : طبق الباحث الاختبار على عينة استطلاعية مؤلفة من (10 ) من طلبة المرحلة الثالثة في قسم اللغة العربية في كلية التربية الاساسية ومن خارج عينة البحث الاساسية، وبأشراف الباحثة بنفسها على التطبيق ، وبعد الانتهاء من الاجابة اتضح وضوح تعليمات الاختبار،

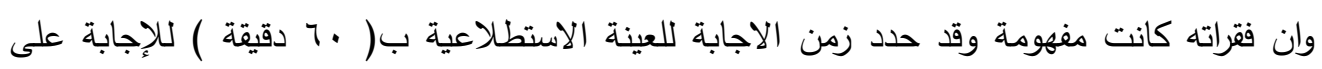

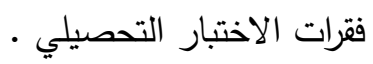
ه- التحليل الاحصائي للفقرات: أي اختبار يجب ان يتصف بالتوازن والاتساق ودرجة مقبولة من الصعوبة وقدرة عالية من التمييز والثبات والاتساق والذي نعني به هنا ان الاختبار يكون ذو علاقة بالموضوع المقاس • (المنيزل

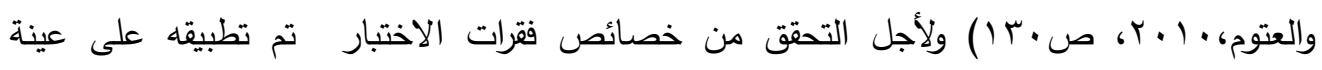
استطلاعية ثانية مكونة من ( . . ( ) طالب وطالبة تم اختارهم عشوائيا من طلبة المرحلة الثالثة في قسم اللغة العربية في كلية التربية الاساسية الجامعة المستتصرية ، ثم صححت إجابات طلبة العينة الاستطلاعية ، ورتبت درجاتهم تتازلياً من أعلى درجة إلى أدنى درجة ، وقمّمت العينة الاستطلاعية

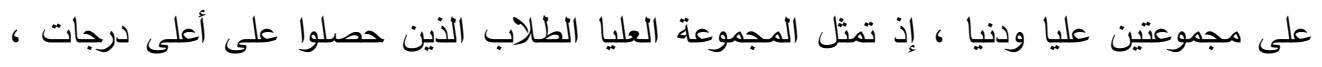
وتمثل المجموعة الدنيا الطلاب الذين حصلوا على أدنى الدرجات ، واعتمدت الباحثة نسبة ( لتمثل المجموعتين الطرفيتين ، وبلغ عدد الطلبة في كل مجموعة (rV) طالب وطالبة .من أفراد كل مجموعة ، وبعدها نظمت الدرجات في جدول ومن ثم احتسب معامل الصعوبة ومعامل التميز على

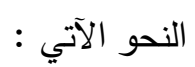

أ- معامل الصعوبة للفقرات: تم حساب معامل الصعوبة لكل فقرة من فقرات الاختبار وقد تراوح بين ( • (- (T, • • ) وهي معاملات جيدة ، اذ ان فقرات الاختبار تعد جيدة اذا تراوح معامل صعوبتها بين

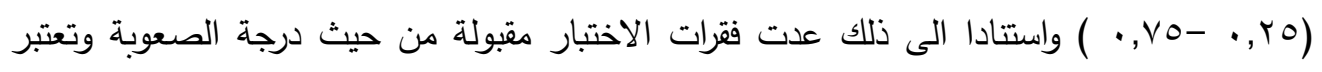

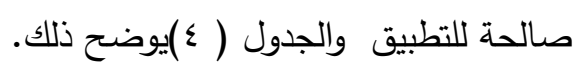

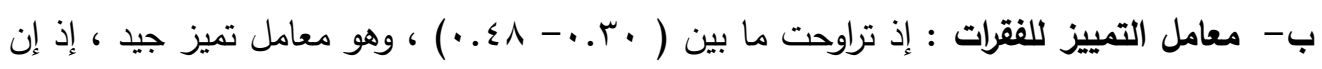

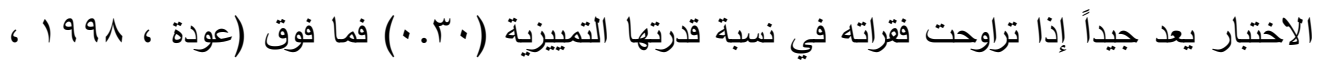
صبوץ) لذا تعد جميع فقرات الاختبار جيدة من حيث قدرتها التميزية وبهذا تم ابقائها جميعا دون حذف او تعديل والجدول (r ) يوضح ذلك. 


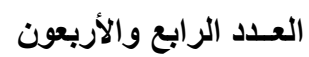

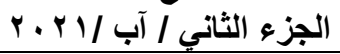

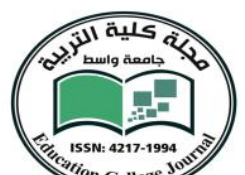

arion College 30

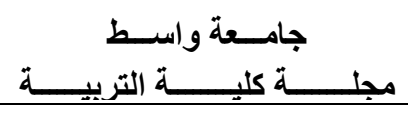

ت - فعالية البدائل الخاطئة ( المموهات) : وعند حساب فعالية البدائل الخاطئة لكل فقرة من فقرات الاختبار من متعدد وجدت الباحثة انها كانت ذات فعالية ، وهذا يعني ان البدائل الخاطئة جذبت اليها عدداً من طلبة المجموعة الدنيا اكثر من طلبة المجموعة العليا وبناء على ذلك تم ابقاء البدائل من دون تغيير والجدول (r) يوضح ذلك جدول ( r r) معاملات الصعوبة والتمييز لفقرات الاختبار ألتحصيلي

\begin{tabular}{|c|c|c|c|c|c|}
\hline معامل التمييز & معامل الصعوبة & رقم & معامل التمييز & معامل الصعوبة & رقم \\
\hline$\bullet, r$. & $\cdot, \varepsilon \wedge$ & YI & rv & $\cdot, T_{1}$ & 1 \\
\hline זr, • & $\cdot, 0 \leqslant$ & Yr & $\cdot, T V$ & $\cdot$, Or & r \\
\hline$\bullet, r$. & $\cdot, \Sigma \wedge$ & rr & אז, • & •, or & $r$ \\
\hline • • & $\cdot, \leqslant \wedge$ & rE & • & $\cdot, \leqslant \wedge$ & $\varepsilon$ \\
\hline$\cdot, r v$ & $\cdot, 0 \leq$ & ro & $\cdot, \leqslant V$ & $\cdot, 79$ & 0 \\
\hline$\bullet$ & $\cdot, \Sigma$ & ry & $\cdot, \Sigma \wedge$ & $\cdot, 0 \mathrm{~V}$ & 7 \\
\hline • & سז, • & rV & $\cdot, \Gamma$ & $\cdot, \Sigma \wedge$ & V \\
\hline سז,• & $\cdot, 0 \leq$ & rᄉ & $\cdot, \leqslant 1$ &., 0 & $\wedge$ \\
\hline • & r, • & $r q$ & • & זr, & 9 \\
\hline • • & $\cdot, \Sigma \wedge$ & r. & • • & $\cdot, \varepsilon \wedge$ & 1. \\
\hline זr, & $\cdot, 0 \leqslant$ & I & זr, & $\cdot, \varepsilon r$ & 11 \\
\hline • • & $\cdot, \leqslant \wedge$ & r & • & $\cdot, \Sigma$ & IT \\
\hline سז, . & $\cdot, 0$ & זr & سז, . & •, or & r \\
\hline • • & $\cdot, \leqslant \wedge$ & rs & $\cdot, \leqslant 1$ & $\cdot, 0 \leqslant$ & $1 \varepsilon$ \\
\hline$\cdot, r V$ & •, Or & ro & זr, & $\cdot, 0 \leqslant$ & 10 \\
\hline • TV & هـ, • & ד r & سז, . & $\cdot, 0$ & 17 \\
\hline • •, & $\cdot, \varepsilon \wedge$ & rV & $\cdot, r V$ & זr, & IV \\
\hline سז, • & $\cdot, 0 \leqslant$ & r^ & • . & $\cdot, \Sigma \wedge$ & 11 \\
\hline سז, • & $\cdot, 0 \leqslant$ & rq & • rV & • rV & 19 \\
\hline$\cdot, \leqslant 1$ & $\cdot, 0$ & $\varepsilon$. & • • & $\cdot, \leq \leqslant$ & r. \\
\hline
\end{tabular}


ثبات الاختبار: ولحساب الثبات طبقت الباحثة هذه المعادلة على عينة التحليل الاحصائي البالغ

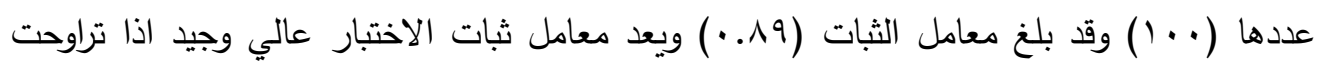

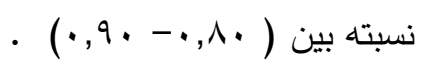

الصورة النهائية للاختبار:

تالف الاختبار بصورته النهائية من (• (؛) فقرة ، اشتملت على نوعين من الفقرات ، (·م) فقرة موضوعية من نوع الاختيار من متعدد، حددت بدرجة واحدة للإجابة الصحيحة وصفر للإجابة الخاطئة اوالمتروكة و( • ( فقرات ) من الاسئلة المقالية حددت بدرجتين تعطى للإجابة النموذجية التي وضعتها الباحثة وتعطى درجة واحدة للإجابة القريبة من الاجابة النموذجية ،وصفر عند الاجابة الخاطئة او المتروكة، وبهذا يتراوح مدى درجات الاختبار التحصيلي من (صفر - - .0 ) بمتوسط دونيه نظري (ro) - ن درجة.

ثانياً: مقياس مهارات التفكير ما وراء المعرفة.

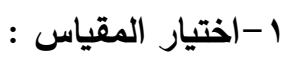

وقد تبنت الباحثة مقياس (الشريدة 0 . r ) لقياس التفكير ما وراء المعرفة للأسباب التالية: ا-ان تقنين المقياس وتطبيقه على طلبة الجامعة والتي هي نفس عينة الدراسة الحالية. r بلم تمض على تطبيق المقياس سنة واحدة . r-جرى التحقق من مؤشرات صدق المقياس على البيئة الجامعية السعودية من خلال عرضة على مجموعة من المحكمين في جامعة ام القرى ، وقد أقر المحكمون فقرات المقياس كما هي ، كما حسب معنب معامل ارتباط بيرسون لكل فقرة والمقياس ككل، وقد تمتعت فقرات المقياس بمعاملات ارتباط مقبولة

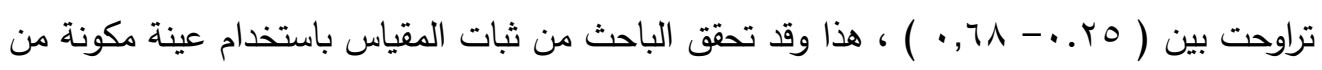
(Y) طالبا وطالبة، من خلال حساب الاتساق الداخلي حسب معادلة كرونباخ ألفا الذي بلغت قيمته

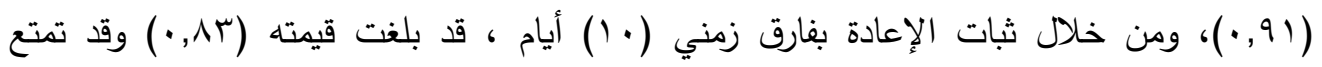
المقياس بمعاملات ثبات مقبولة. ومن أجل إعداد المقياس وتقنينه ليتناسب مع البيئة العراقية أتبعت الباحثة الخطوات التالية:

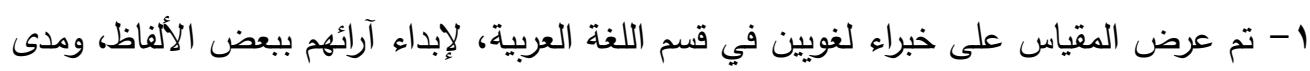
مناسبتها للطلبة في بيئة الدراسة، وقد اتفق المدققين على إن فقرات المقياس سليمة لغوياً وواضحة وتتتاسب مع البيئة العراقي ولم تجري أي تعديلات عليه. 
ץ - وللتحقق من صدق المقياس الظاهري تم توزيعه على مجموعة من الخبراء والمتخصصين في قسم العلوم التربوية والنفسية وطلبت منهم عطاء آرائهم في سلامة فقراته، وملائمتها للأبعاد ،التي تشير اليها، وهل هي واضحة ومفهومة المعنى وهل تقيس ما وضعت من اجله. وقد اتقق جميع المحكمين على صلاحية المقياس وبنسبة اتفاق( 99V ) ) . r- وتم التحقق من ثبات المقياس بتطبيقه على عينة مكونة من(·ـ) طالباً وطالبة من غير عينة البحث الأساسية ، وبعد مرور اسبوعان تمت اعادة التطبيق على نفس العينة ، فوجد أن معامل الارتباط بيرسون بلغ (1/.) وهذا يعني ان قيمة معامل الثبات ذات دلالة إحصائية وبذلك يكون

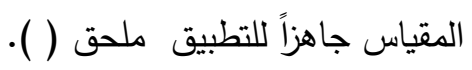
تتفيذ التجربة بعد تهيئة مستلزمات الدراسة واعداد أدواتها، بدأت الباحثة بالتطبيق الفعلي للتجربة بتاريخ

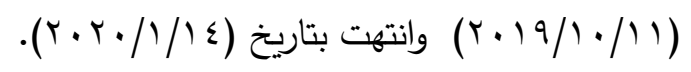
الوسبائل الاحصائية: لمعالجة البيانات استخدمت الباحثة الحقيبة الإحصائية للعلوم الاجتماعية(spss) في معالجة البيانات. الفصل الرابع

\section{عرض النتائج وتفسيرها اولا: عرض النتائج}

تبنت الباحثة خطوات علمية وإجراءات منهجية لنقل مشكلة البحث الحالي الخاصة بالوقوف على فاعلية استراتيجية التدريس التبادلي في تحصيل مادة طرائق تدريس اللغة العربية وتنمية مهارات التفكير ما وراء المعرفة لدى طلبة قسم اللغة العربية في جامعة بابل إلى حيز البحث والتطبيق وذلك لتحقيق جملة من الأهداف والفرضيات القابلة للمعالجة والتحقق، فجاءت المعالجة في ضوء أهداف

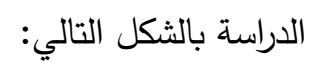
الهرف الاول: (التعرف على فاعلية استراتيجية التدريس التبادلي في تحصيل مادة طرائق تدريس (اللغة العربية لاى مجموعتي البحث ( التجربية والضابطة)).. ولتحقيق هذا الهدف سيتم اختبار الفرضيات الصفرية مقابل فرضياتها البديلة:" لا توجد فروق ذات دلالة إحصائية بين متوسط درجات القياس البعدي لأفراد المجموعة التجربيية التي درست باستراتيجية التدريس التبادلي، ومتوسط درجات القياس البعدي للمجموعة الضابطة التي درست بالطريقة التقليدية وبمستوى دلالة (0. . •) على الاختبار التحصيلي لمادة طرائق تدريس اللغة العربية . 
قامت الباحثة بمعالجة بيانات القياس البعدي لأفراد المجوعتين التجريبية والضابطة على

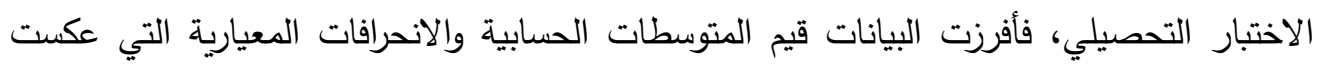

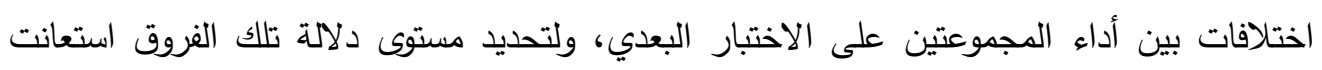

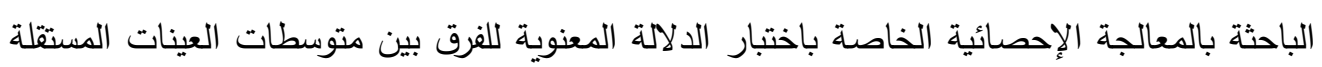

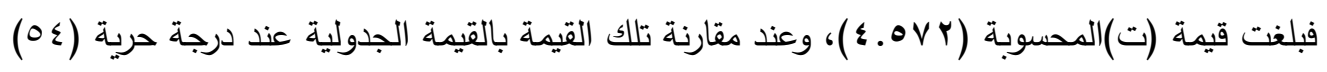

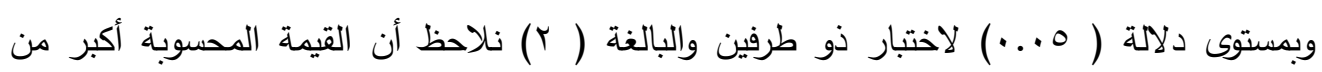

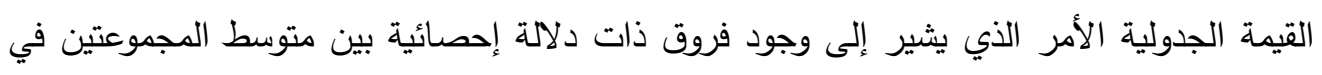

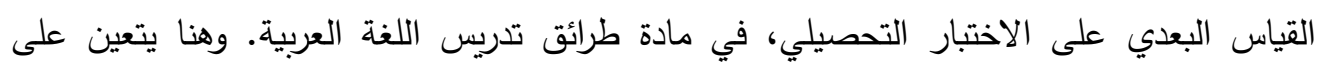

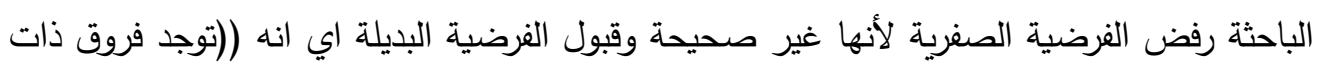

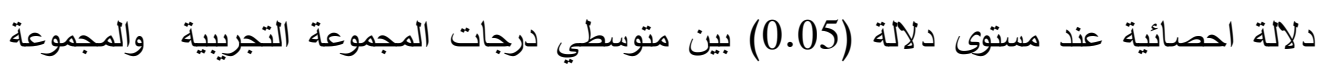

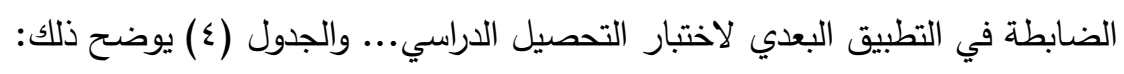

جدول (ع)

"قيم المتوسطات الحسابية والانحرافات المعيارية والقيمة التائية ومستوى دلالة الفرق بين القياسات

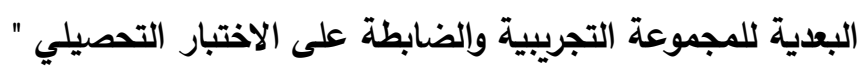

\begin{tabular}{|c|c|c|c|c|c|c|}
\hline مستوى دلالة الفرق & الجديمة الجدلية & التائية & المعياري & الحستوسط & العينة & المجموعة \\
\hline \multirow{2}{*}{ 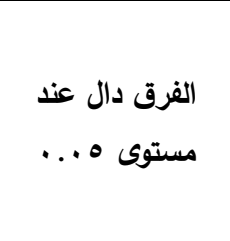 } & \multirow{2}{*}{$r$} & \multirow{2}{*}{ \&.OVY } & $r .171$ & rצ.AY & $r \Lambda$ & التجريبية \\
\hline & & & $\varepsilon .97 \leqslant$ & $r r .1 \leqslant r$ & $r^{\Lambda}$ & الضابطة \\
\hline
\end{tabular}

الههف الثاني: (التعرف على أثر استراتيجية التدريس التبادلي في تنمية مهارات التفكير ما وراء

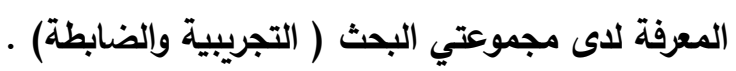

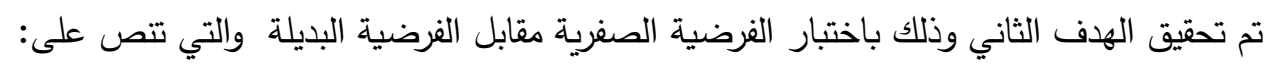
الفرض الأول" لا توجد فروق ذات دلالة إحصائية بين درجات القياسات القبلية والبعدية لأفراد

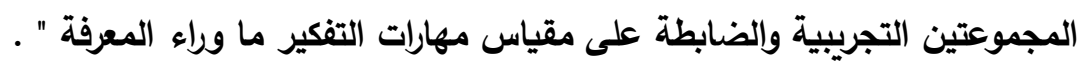


للوقوف على الفروق بين القياسات القبلية والبعدية للمجموعتين التجريبية والضابطة، قامت الباحثة بمعالجة تلك البيانات باستخدام اختبار تحليل التباين الأحادي إذ بلغت النسبة الفائية المحسوبة بين

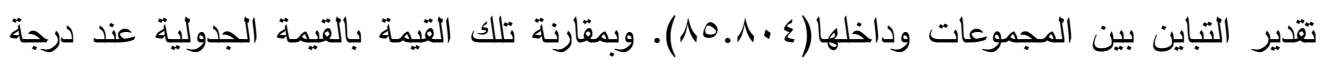

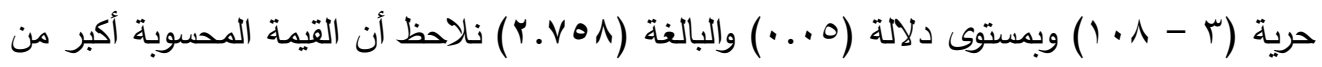
القيمة الجدولية الأمر الذي يشير إلى وجود فروق دالة إحصائيا بين المجموعات وداخل المجموعات. والجدول (0) يوضح ذلك:

جدول (0)

(جدول تحليل التباين لبيانات القياسات القبلية والبعدي للمجموعتين التجريبية والضابطة على مقياس

\begin{tabular}{|c|c|c|c|c|c|}
\hline \multicolumn{2}{|c|}{ القيمة الفائية } & \multirow{2}{*}{ متوبط المربعات } & \multirow{2}{*}{ الحرية } & \multirow{2}{*}{ مجموع مربعات } & \multirow{2}{*}{ مصدر } \\
\hline الجدولية & المحسوبة & & & & \\
\hline \multirow{3}{*}{$r . v \bullet \Lambda$} & \multirow{3}{*}{${ }^{*} \wedge \bullet . \wedge \cdot \varepsilon$} & $\Lambda r q \mid r . \leqslant r r$ & $r$ & $r \leqslant \Lambda V \leqslant \ldots r q q$ & بين المجموعات \\
\hline & & $997 . \% 1 \leq$ & 1.1 & 1. & داخل المجموعات \\
\hline & & & 111 & ror,l r.r.r. & الكلي \\
\hline
\end{tabular}

مهارات التفكير ما وراء المعرفة)

ومن الجدول (0) نكون قد حصلنا على قيمة فائية دالة عند مستوى (0. . • ) ومن ثم يقبل الفرض البديل، حيث أصبح من الضروري معرفة أي القياسات في المجموعتين هي المسئولة عن ظهور هذا Studentized ) الفرق،وللتعرف على تلك الفروق اعتمدت الباحثة أسلوب المقارنات المتعدد باستخدام (Rang ، حيث رتبت متوسطات القياسين القبلي والبعدي للمجموعتين التجريبية والضابطة تتازلياً

وكما في جدول (†) 
العـدد الرابع والأربعون

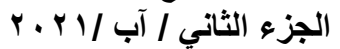

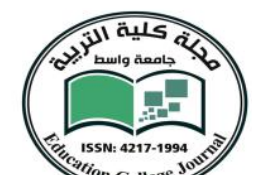

rion College 30

\section{جامسـعة واســط

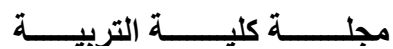

جدول (†) (المجموعتين التجريبية والضابطة وقيم المتوسطات الحسابية والانحرافات المعيارية للقياس القبلي والبعدي على مقياس مهارات التفكير ما وراء المعرفة)

\begin{tabular}{|c|c|c|c|c|}
\hline \multicolumn{2}{|c|}{ المجموعة الضابطة } & \multicolumn{2}{|c|}{ المجموعة التجريبية } & \\
\hline بعدي & قبلي & بعدي & قبلي & \\
\hline 04 & $\begin{array}{l}r \wedge \\
r \wedge\end{array}$ & rA & rA rAr & العينة \\
\hline VT.TOV & $\vee V . \leqslant Y q$ & $\mid \wedge$ ห.r| & VA.rqu & المتوسط \\
\hline 9.0Y1 & $10 . r \leq r$ & $r . . \leqslant r r$ & Ir.Aro & الانحراف \\
\hline
\end{tabular}

ثم حسبت الفروق بين المجموعات فحصلنا على النتائج التالية:

جدول رقم (V) قيم Q المحسوبة للمقارنات المتعددة باستخدام مدى ستيودنت بين نتائج القياس القبلي والبعدي على مقياس مهارات التفكير ما وراء المعرفة)

\begin{tabular}{|c|c|c|c|c|}
\hline قـ بـ ت & قـ ض ق & قـ ق ت & قـ ضب ض & \\
\hline & $* * 1 \wedge .01 \mathrm{~V}$ & $* * 1 \wedge . r \Delta r$ & $* * 11.799$ & مج ت ق.ب \\
\hline & & $* . .17 \varepsilon$ & $* . . r \leqslant V$ & مج ض ق.ق \\
\hline & & & $* . .1 \wedge r$ & مـج ت ق.ق \\
\hline & $r Q Q=r . v r$ & $r Q=\varepsilon . r \varepsilon$ & $\leqslant Q=\leq .0 \leqslant \theta$ & قيم Qالحرجة \\
\hline
\end{tabular}

وبالرجوع إلى جدول توزيع (q) المدى المنسوب إلى (Studentized) وبدرجة حرية (108) وعند

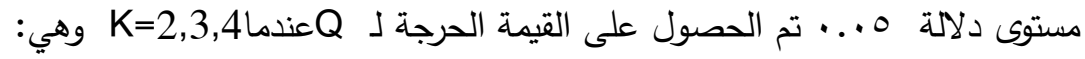
Q2 $=r . v r \quad Q 3=\varepsilon . r \leq Q Q$ Q4 $=\varepsilon .0 \leq 0$ * مقارنات قيم Q المحسوبة بالقيم الحرجة لـ Q في الصف الأول: وبمقارنة قيم الصف الأول في الجدول أعلاه مع قيمة Q الحرجة، ظهر أن أعلى قيمة في الصف الأول هي(19.19.19) والمتضمنة قيمة Q المحسوبة بين القياس البعدي للمجموعتين التجريبية

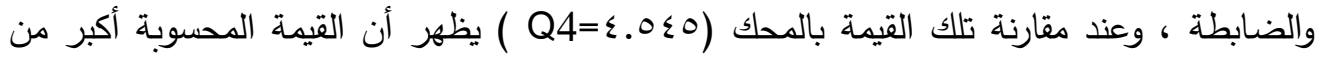
القيمة الحرجة الأمر الذي يرجح دلالة الفروق عند مستوى(0 . . ..) ثم ننتقل لمقارنة القيمة الثانية في 


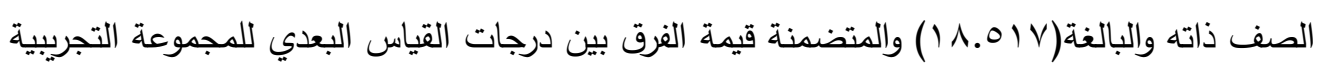
والقياس القبلي للمجموعة الضابطة بقيمة المحك (ع ب.ء =Q3)، وقد كان الفرق دالاً أيضا لكون القيمة المحسوبة أكبر من القيمة الحرجة للمحك، وفي ضوء قيم المتوسطات سجل الفرق لصالح القياس البعدي للمجموعة التجريبية في الحالتين ، أما القيمة الأخيرة في الصف ذاته والبالغة

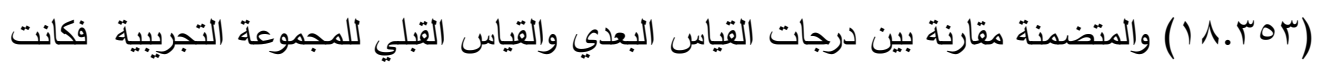
اكبر من قيمة المحك(UT) الأمر الذي يشير إلى وجود فروق دالة احصائياً بين القياسين

للمجموعة التجريبية. * مقارنات قيم Q المحسوبة بالقيم الحرجة لـ Q في الصف الثاني: ثم انتقلت الباحثة لإجراء المقارنات لقيم الصف الثاني بدءًا من أولها والبالغة (V乏 مقارنة القياس القبلي للمجموعة التجريبية والقياس البعدي للمجموعة الضابطة، مع المحك (Q4=§.0 فكان الفرق بينهما غير دال إحصائياً لأن القيمة المحسوبة كانت أصغر من القيمة الحرجة للمحك، وعليه توقف باقي المقارنات في الصف الثاني.

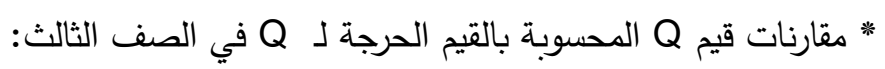
وأخيرا أجرت الباحثة مقارنة لقيمة الصف الأخير والوحيدة البالغة (rی ( . ) والمتضمنة مقارنة نتائج

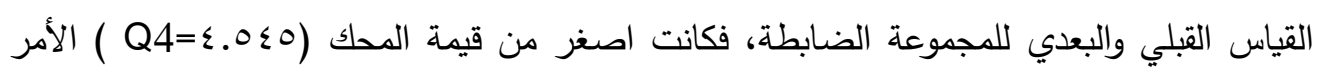
الذي يشير إلى عدم وجود فروق دالة إحصائيا بين القياسين. الفرض الثاني: لا توجد فروق ذات دلالة إحصائية بين درجات القياسات القبلية والبعدية لأفراد المجموعتين التجريبية والضابطة على مهارة التظيم بإتباع ذات الإجراء قامت الباحثة بمعالجة

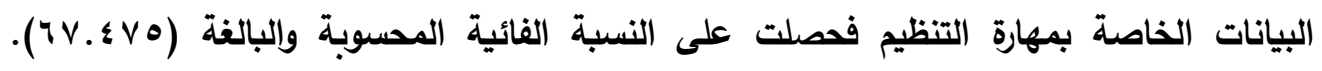
وبمقارنة تلك القيمة بالقيمة الجدولية عند درجة حرية (r -1 • 1) وبمستوى دلالة (ه ...

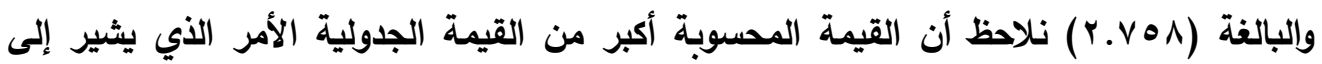
وجود فروق دالة إحصائيا بين قياسات المجموعتين • والجدول ( • 1 ) يوضح ذلك: 
العزء الثداند الرابع والأربعون

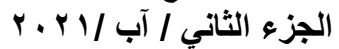

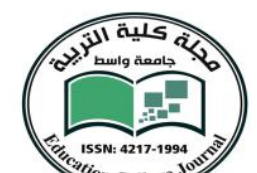

irion College

$$
\text { جامسعة واســط }
$$

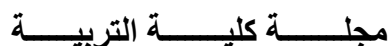

جدول (^) (جدول تحليل التباين لبيانات القياسات القبلية والبعدي للمجموعتين التجريبية والضابطة على

مهارة التنظيم)

\begin{tabular}{|c|c|c|c|c|}
\hline الفائية & تقدير & الحرية & مجموع مربعات الانحرافات & مصدر \\
\hline \multirow[t]{3}{*}{ *ฯ } & MOTr.VYI & $r$ & 1.791 .174 & بين المجموعات \\
\hline & Or.A10 & 1.1 & $O V \cdot \varepsilon \ldots r$ & داخل المجموعات \\
\hline & & 111 & $18, r 90.1 \wedge r$ & الكلي \\
\hline
\end{tabular}

وللوقوف على أي القياسات في المجموعتين هي المسؤولة عن ظهور هذا الفرق، اعتمدت الباحثة أسلوب المقارنات المتعدد باستخدام (Studentized Rang) ، حيث رتبت متوسطات القياسين القبلي والبعدي للمجموعتين التجرببية والضابطة تنازلياً :

جدول(9) أحجام المجموعتين التجريبية والضابطة وقيم المتوسطات الحسابية والانحرافات المعيارية للقياس القبلي والبعدي على مهارة التنظيم)

\begin{tabular}{|c|c|c|c|c|}
\hline \multicolumn{2}{|c|}{ المجموعة الضابطة } & \multicolumn{2}{|c|}{ المجموعة التجريبية } & \\
\hline بعدي & قبلي & بعدي & قبلي & \\
\hline$r \wedge$ & r^ & r^ & r^ & العينة \\
\hline r^. IVq & Y.AYI & $0.97 \leq$ & rV.Vo. & المتوسط \\
\hline A.MI & $\mathrm{V} .00 \mathrm{~V}$ & V.PY & $7 . v \cdot r$ & الانحراف \\
\hline
\end{tabular}

ثم حسبت الفروق بين المجموعات فحصلنا على النتائج التالية: 
جدول رقم (• (1) Q Q المحسوبة للمقارنات المتعددة باستخدام مدى ستيودنت بين نتائج القياس

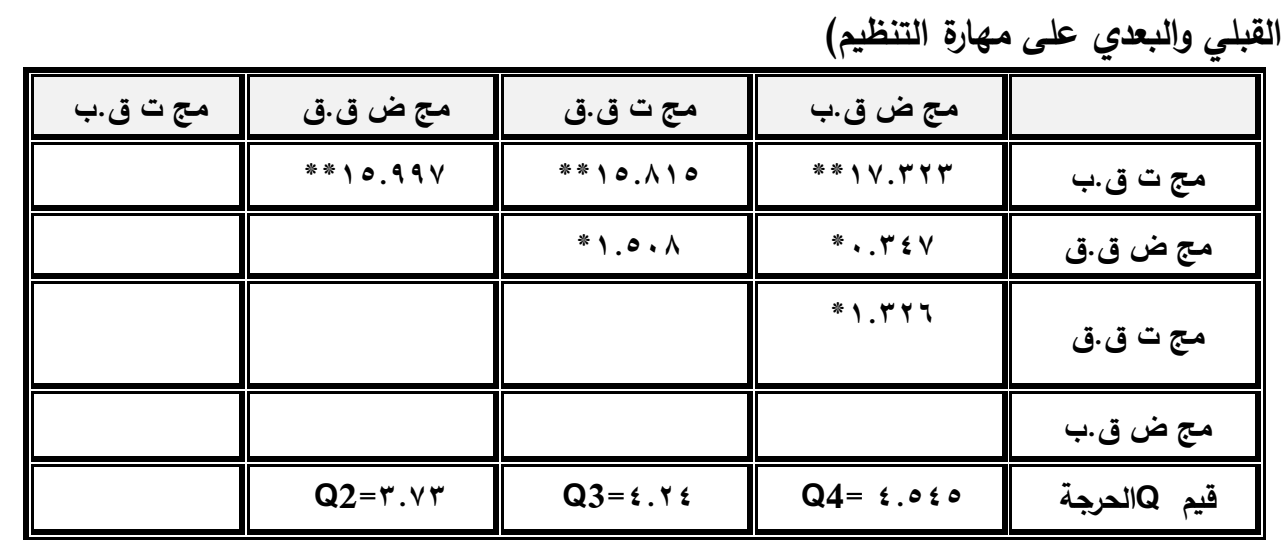

* ومن مقارنة القيم المحسوبة بالقيم الحرجة لـ Q حصلت الباحثة على النتائج التالية: - توجد فروق ذات دلالة إحصائية بين :

نتائج القياس البعدي للمجموعة التجريبية وكل من القياس البعدي بلإين للمجموعة الضابطة والقياسيين

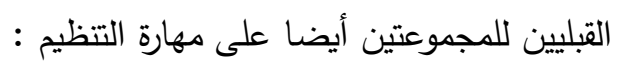

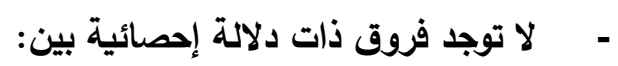

نتائج القياس القبلي والبعدي للمجموعة الضابطة، ونتائج القياس القبلي للمجموعتين ، ونتائج القياس القبلي للمجموعة التجريبية والقياس البعدي للمجموعة الضابطة على مهارة التنظيم .

الفرض الثالث: " لا توجد فروق ذات دلالة إحصائية بين درجات القياسات القبلية والبعدية لأفراد

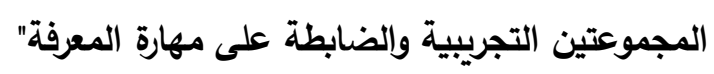

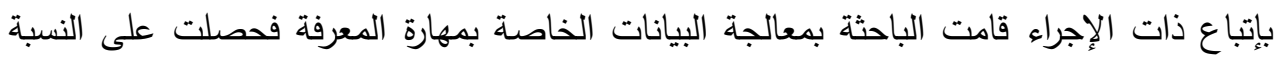

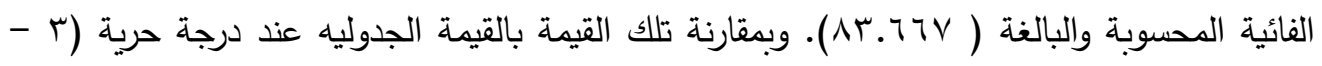

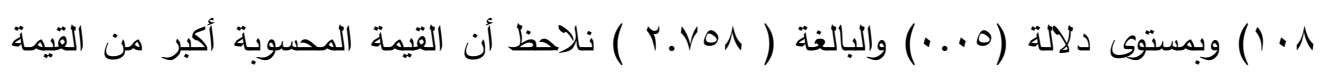
الجدوليه الأمر الذي يشير إلى وجود فروق دالة إحصائيا بين قياسات المجموعتين ـ والجدول (1') (1) يوضح ذلك: 


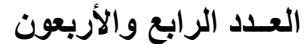

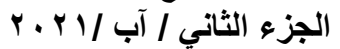

جامــعة واســـ كلــ

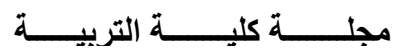

جدول (11) (جدول تحليل التباين لبيانات القياسات القبلية والبعدي للمجموعتين التجريبية والضابطة على مهارة المعرفة

\begin{tabular}{|c|c|c|c|c|}
\hline النفائية & تقدير & الحربة & مجموع مربعات الانحرافات & مصدر \\
\hline \multirow{3}{*}{ *人น.ฯษ } & $r q \leq \Lambda .7 \vee \leqslant$ & r & $11 \wedge \leq 4 . . r r$ & بين المجموعات \\
\hline & $\leqslant v .190$ & 1.1 & $0.9 V . .7 \leqslant$ & داخل المجموعات \\
\hline & & 111 & $17,9 \leq r . . \wedge V$ & الكلي \\
\hline
\end{tabular}

وباعتماد أسلوب المقارنات المتعدد باستخدام

رتبت متوسطات القياسين القبلي والبعدي للمجموعتين التجريبية (Studentized Rang) والضابطة تنازليا، للوقوف على أي القياسات في المجموعتين هي المسئولة عن ظهور هذا الفرق:

جدول(r ا) (أحجام المجموعتين التجريبية والضابطة وقيم المتوسطات الحسابية والانحرافات المعيارية للقياس القبلي والبعدي على مهارة المعرفة) ثم حسبت الفروق بين المجموعات فحصلنا على النتائج التالية:

\begin{tabular}{|c|c|c|c|c|}
\hline \multicolumn{2}{|c|}{ المجموعة الضابطة } & \multicolumn{2}{|c|}{ المجموعة التجريبية } & \\
\hline بعدي & قبلي & بعدي & قبلي & \\
\hline rᄉ & rᄉ & r^ & rA & العينة \\
\hline r^.।Vq & rצ.AYI & $01.97 \varepsilon$ & $r \ldots . .$. & المتوسط \\
\hline A.rIE & $V .00 \mathrm{~V}$ & V..YY & Y.Y11 & الانحراف \\
\hline
\end{tabular}




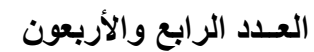

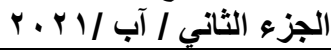

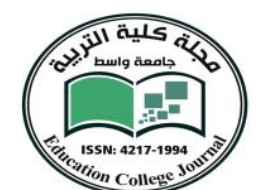

جدول رقم (ب I) (قيم Q المحسوبة للمقارنات المتعددة باستخدام مدى ستيودنت بين نتائج القياس القبلي

والبعدي على مهارة المعرفة)

\begin{tabular}{|c|c|c|c|c|}
\hline مج ت ق.ب & مج ض ق.ق & مج ت ق.ق & مج ض. ق.ب & \\
\hline & $* * 1 \wedge . r \vee q$ & $* * \mid \vee . \wedge \wedge \leq$ & $* * 1 \wedge . \curlyvee \ldots$ & مج ت ق.ب \\
\hline & & $* . . \leqslant 90$ & $* . . v 17$ & مج ض ق.ق \\
\hline & & & *..rr. & مج ت ق.ق \\
\hline & & & & مج ض ق · ب \\
\hline & $\mathbf{Q 2}=r . v r$ & $\mathbf{Q 3}=\varepsilon . r \leq$ & $Q 4=\leq .0 \leqslant 0$ & قيم Q|لحرجة \\
\hline
\end{tabular}

* ومن مقارنة القيم المحسوبة بالقيم الحرجة ل Q حصلت الباحثة على النتائج التالية: - توجد فروق ذات دلالة إحصائية بين : نتائج القياس البعدي للمجموعة التجريبية وكل من القياس البعدي للمجموعة الضابطة والقياسيين القبليين للمجموعتين أيضا. - ل الا توجد فروق ذات دلالة إحصائية بين نتائج :

- القياس القبلي للمجموعة الضابطة، وكل من نتائج القياس القبلي والبعدي للمجموعة الضابطة. - نتائج القياس القبلي والبعدي للمجموعة الضابطة. الفرض الرابع" (لا توجد فروق ذات دلالة إحصائية بين درجات القياسات القبلية والبعدية لأفراد المجموعتين التجريبية والضابطة على مهارة المعالجة.) كما قامت الباحثة بمعالجة البيانات الخاصة بمهارة المعالجة فبلغت النسبة الفائية المحسوبة

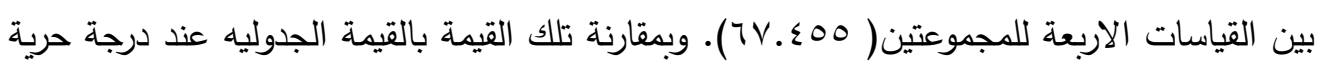

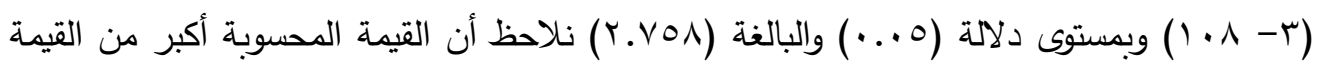
الجدوليه الأمر الذي يثير إلى وجود فروق دالة إحصائيا بين قياسات المجموعتين • والجدول (ع () يوضـح ذلك: 
العــد الرابع والأربعون

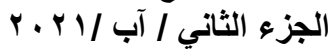

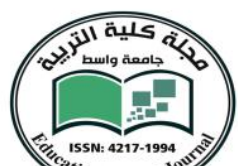

irion College

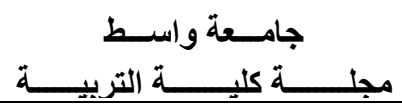

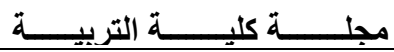

\section{جدول ( 1 ( )}

(جدول تحليل التباين لبيانات القياسات القبلية والبعدي للمجموعتين التجرببية والضابطة على مهارة (المعالجة)

\begin{tabular}{|c|c|c|c|c|}
\hline الفائية & مصدر التباين & درجة الحرية & مجموع مربعات الانحرافات & مصدر \\
\hline \multirow[t]{2}{*}{$* 7 V . \leq 00$} & roqr.VYו & $r$ & 1.791 .174 & بين المجموعات \\
\hline & OY.AMI & $1 \cdot 1$ & $\bullet \vee \cdot 0 . V \wedge \varepsilon$ & داخل المجموعات \\
\hline & & 111 & $17+97.9 \leq V$ & \\
\hline
\end{tabular}

وباعتماد أسلوب المقارنات المتعدد باستخدام (Studentized Rang) رتبت متوسطات القياسين

القبلي والبعدي للمجموعتين التجريبية والضابطة تتازليا.كما هو موضتح بجدول رقم (10)

\section{جدول (10)}

( أحجام المجموعتين التجريبية والضابطة وقيم المتوسطات الحسابية والانحرافات المعيارية للقياس القبلي والبعدي على مهارة المعالجة)

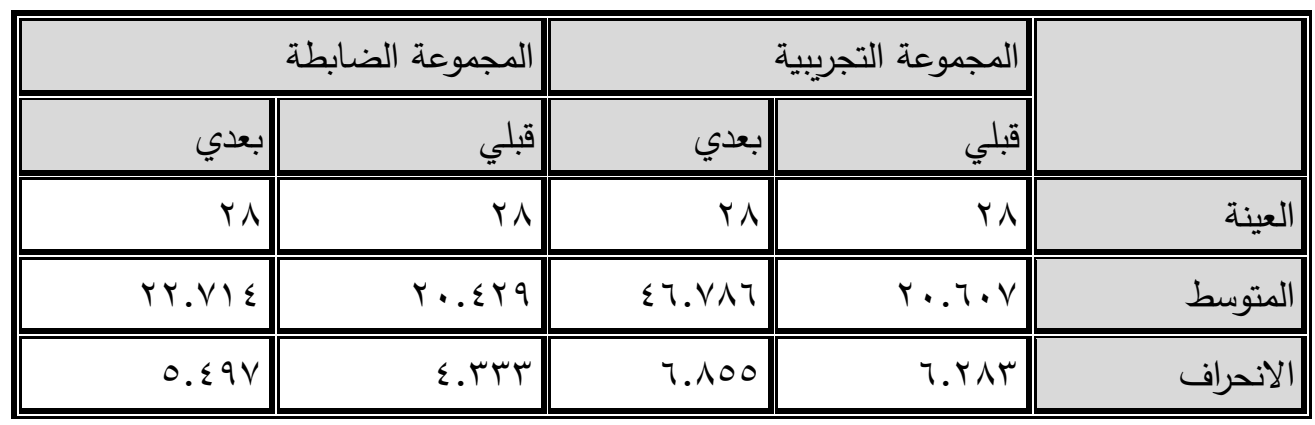

ثم حسبت الفروق بين المجموعات فحصلنا على النتائج التالية: 


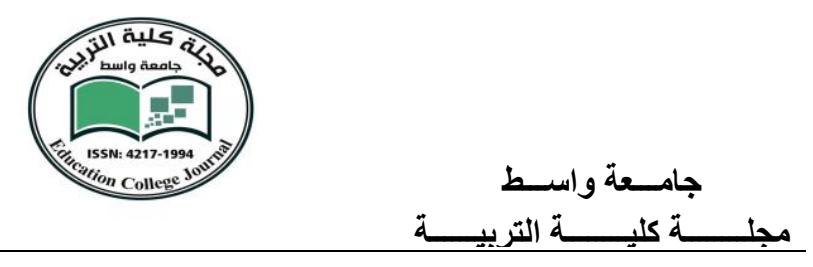

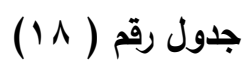

قيم Q المحسوبة للمقارنات المتعددة باستخدام مدى ستيودنت بين نتائج القياس القبلي والبعدي على مهارة المعالجة

\begin{tabular}{|c|c|c|c|c|}
\hline مج ت ق.ب & مج ض ق.ق & مج ت ق.ق & مج ض ق. ب & \\
\hline & $* * 19 \ldots$ or & $* * 1 \vee .019$ & $* * 19.1 \wedge r$ & مجج ت ق.ب \\
\hline & & *1.0rT & " & مج ض ق.ق \\
\hline & & & $* . .1 r 9$ & مج ت ق. ق \\
\hline & & & & مج ض ق.ب \\
\hline & $\mathbf{Q 2}=r . v r$ & $\mathbf{Q 3}=\{. Y \xi$ & $\mathbf{Q 4}=\leq .0 \leqslant 0$ & قيم Qالحرجة \\
\hline
\end{tabular}

* ومن مقارنة القيم المحسوبة بالقيم الحرجة لـ Q حصلت الباحثة على النتائج التالية: - توجد فروق ذات دلالة إحصائية بين :

نتائج القياس ألبعدي للمجموعة التجريبية وكل من القياس دئ ألبعدي للمجموعة الضابطة والقياسيين القبليين للمجموعتين أيضا. - ل التوجد فروق ذات دلالة إحصائية بين: - نتائج القياس البعدي للمجموعة الضابطة، وكل من نتائج القياس القبلي للمجموعتين التجريبية والضابطة . نتائح - نتائج القياس القبلي للمجموعتين. وبهذه النتيجة التي بينت ان هنالك فرق بين أفراد المجموعة التجريبية وبين أفراد الدجموعة الضابطة في نتائج القياس البعدي لمهارات التنكير ماوراء المعرفة ولصالح المجموعة التجريبية ، لتعطي دليلا

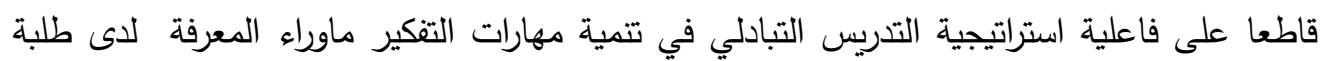

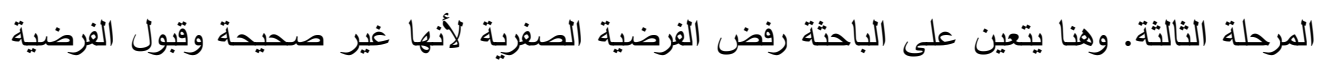


ثانيا : تفسير النتائج:

1- النتائج المتعقة بالتحصيل الدراسي لمادة طرائق تدريس اللغة العربية لاى طلبة المرحلة

$$
\text { وتعزي الباحثة السبب في ذلك الى: الريعة }
$$

1- ان استراتيجية التدريس التبادلي كانت أكثر فاعلية في تتمية التحصيل الدراسي لانها تسهم في

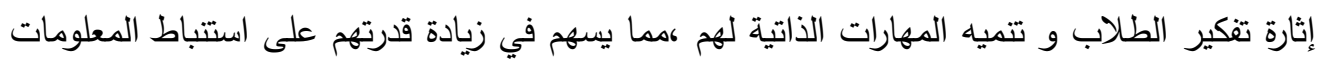

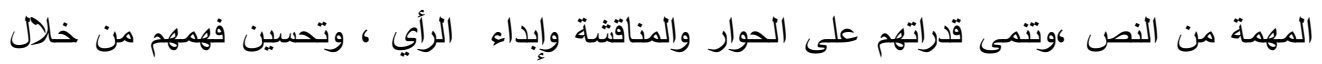

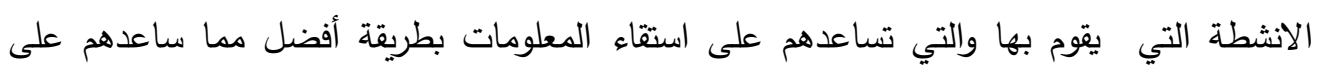

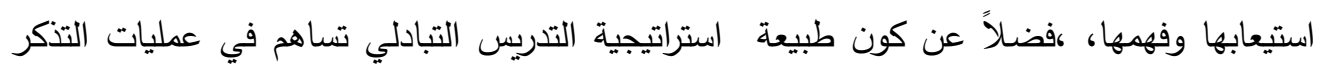
والاحتفاظ بالتعلم لمدى طويل. r- وكذلك ان استراتيجية التدريس التبادلي هي أحد النماذج البنائية في التدريس التي تسهم في إثارة

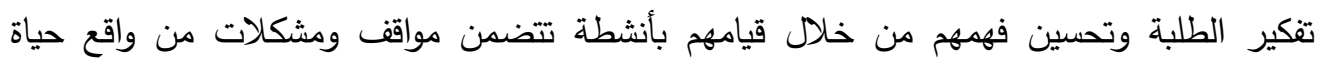
الطالب، والتي من خلالها يتم الربط بين المعلومات ذات العلاقة المشتركة والقدرة على التنسير والتتبؤ •

ץ- النتائج المتعلقة باثر استراتيجية التدريس التبادلي في تنمية مهارات التفكير ماوراء المعرفة

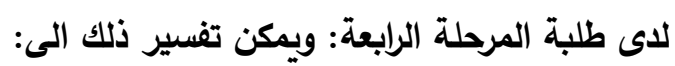

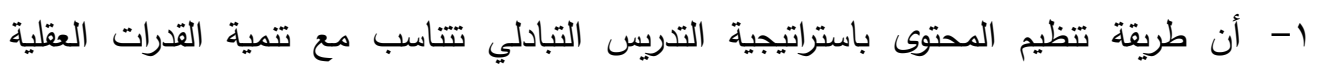
والتنكير للطلاب في المرحلة الجامعية .

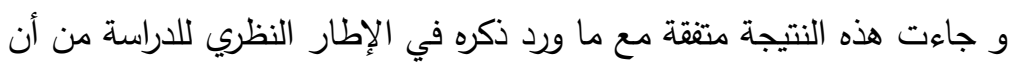

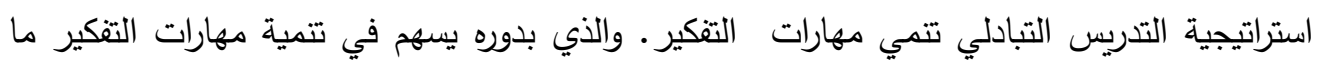

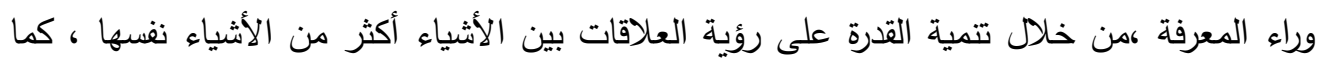

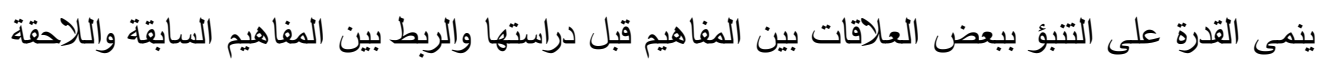

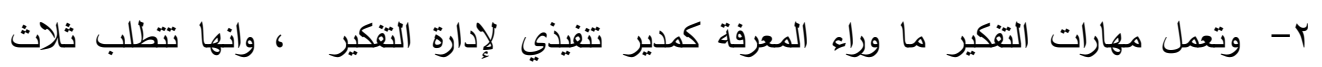

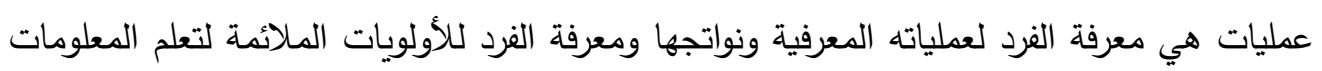
وضبط وتتظيم ومعالجة وتقويم العمليات المعرفية . 
ثالثا: التوصيات: The Recommendations

في ضوء نتائج البحث الحالي توصي الباحثة بما يلي :

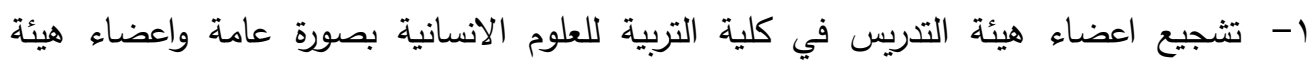

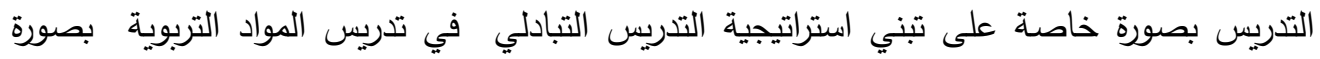

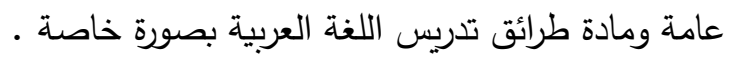

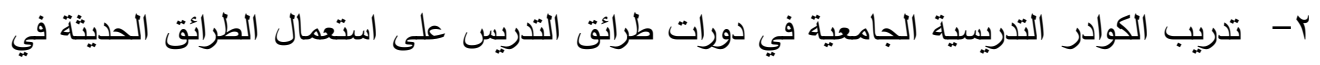

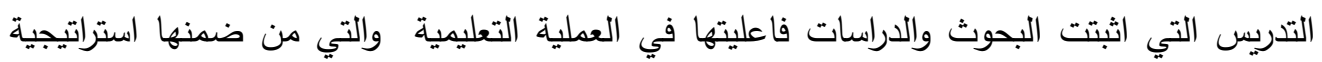
التدريس التبادلي وخطوات تطبيقها .

The Suggestions : المقترحات

استكمالاً للبحث الحالي تقترح الباحثة إجراء الدراسات الآتية: 1- اجراء مزيد من البحوث المماثلة للبحث الحالي على مراحل دراسية اخرى ( الابتدائية ،

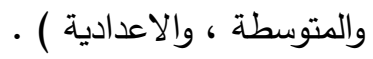

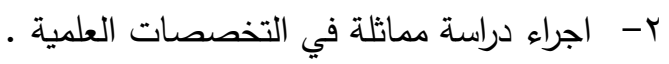
المصادر اولا : المصادر العربية: - المبراد - - - القران الكريم

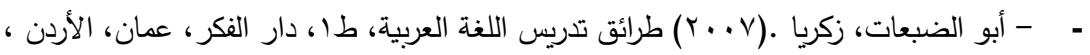

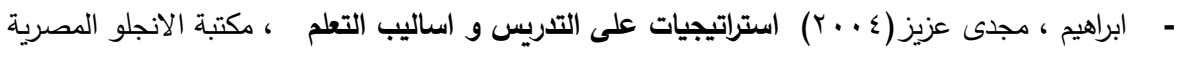

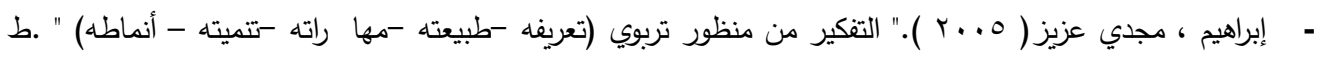

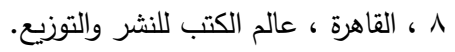

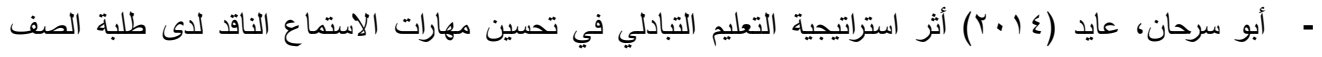

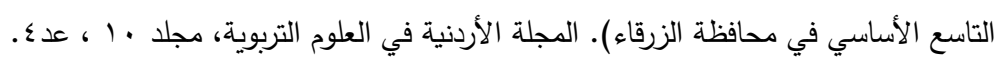

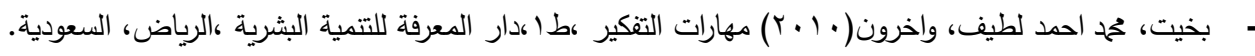

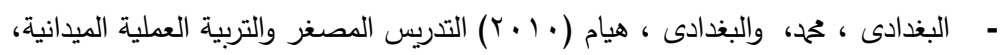

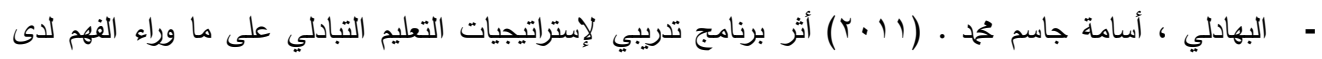

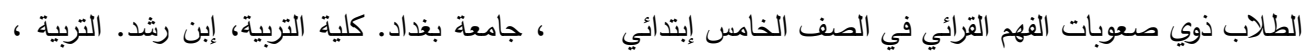

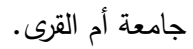
- بهجات, رفعت محمود, ( 2001 ) ت تدريس العلوم الطبيعية- رؤية معاصرة, ط ,2 القاهرة عالم الكتب للطبع والنشر .

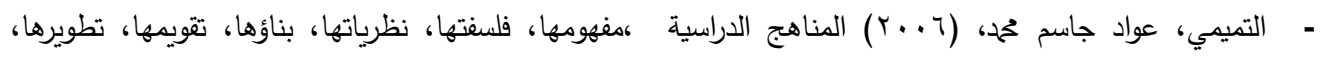
تتقيحها، مكتب الفنون للتحضير الطباعي ، بغداد، العراق. 
- جابر ،عبد الحميد جابر :(991 (1)" التدريس و التعلم الاسس النظرية و الاستراتيجية و الفاعلية " ، دار الفكر العربي

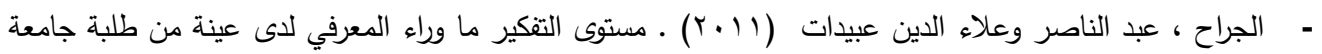

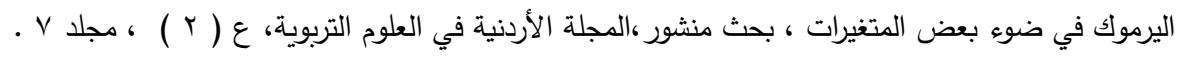

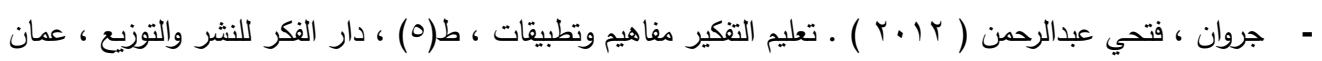

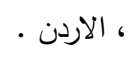

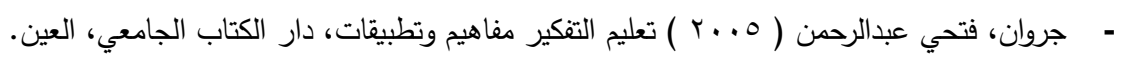

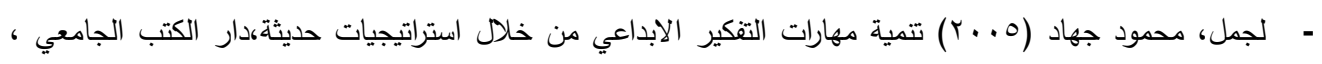
العين، الامارات العربية المتحدة.

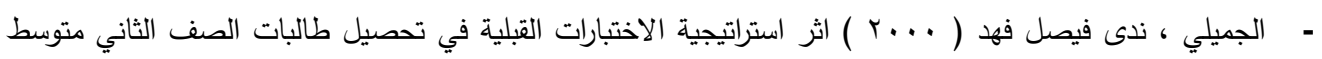

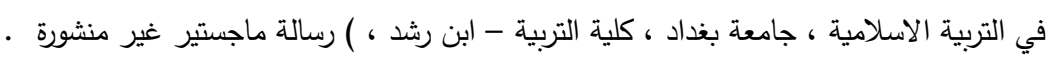

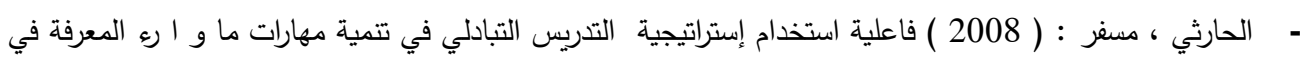
القراءة لاى طلاب المرحلة الثانوية ، رسالة ماجستير غير منشورة .

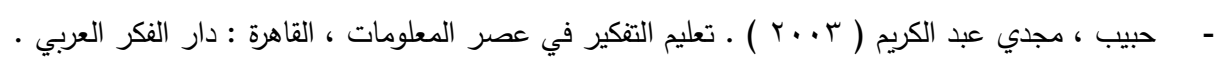

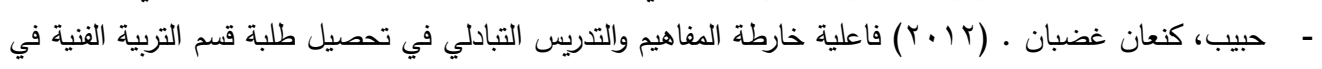
مادة تاريخ الفن الحديث، جامعة بغداد. كلية الفنون الجميلة.

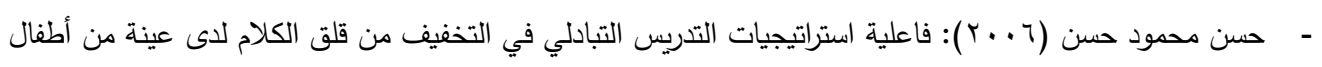

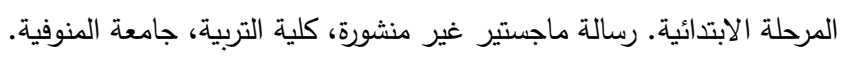

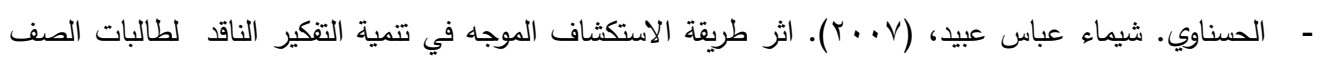

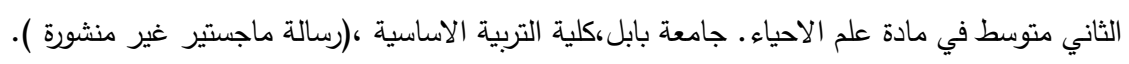

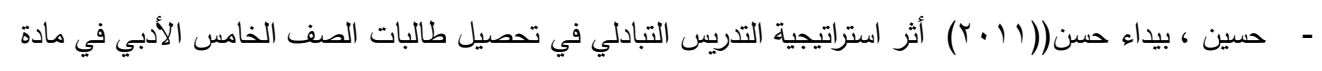
الأدب والنصوص، رسالة ماجستير، جامعة ديالى، كلية التربية للعلوم الإنسانية.

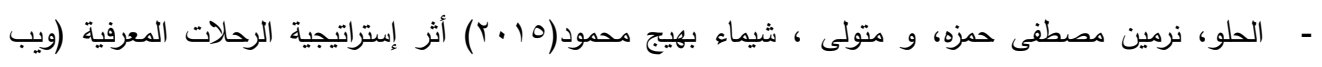

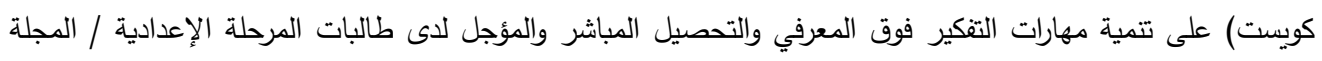

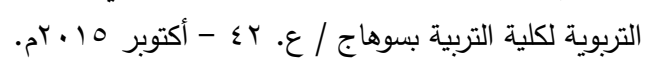

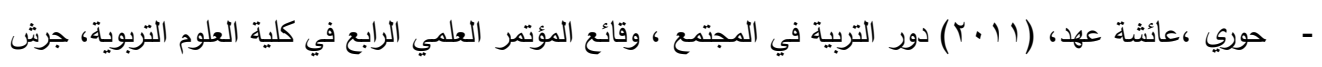

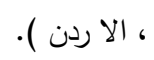

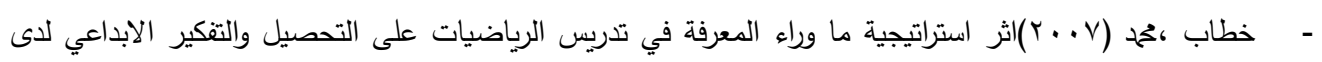

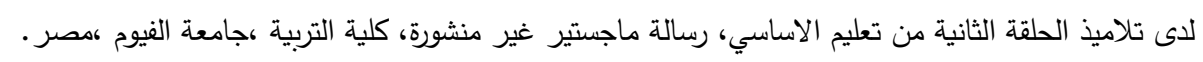

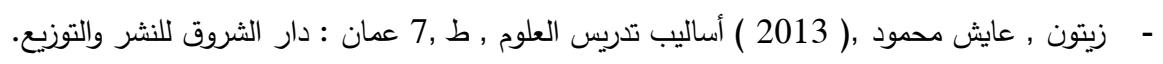

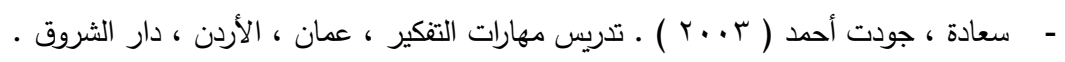

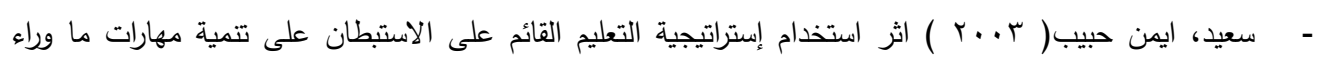
المعرفة لاى طلاب الصف الأول الثانوي من خلال الثين الثيزياء، مجلة المعلم. 


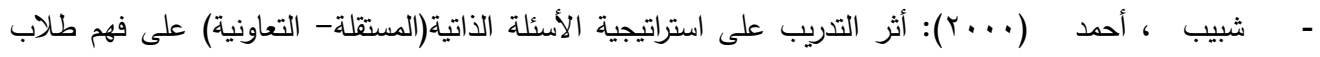

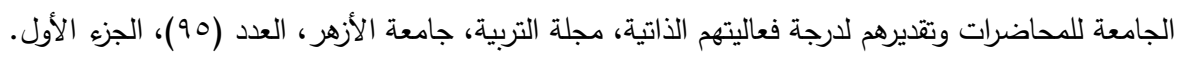

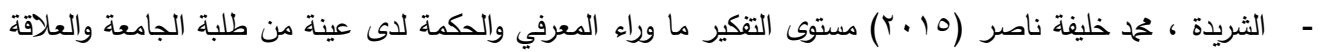

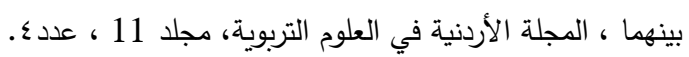

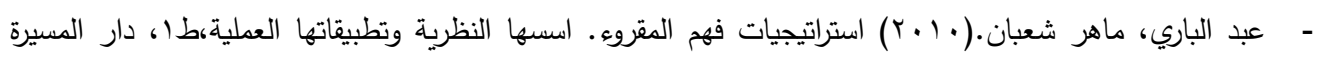
للنشر والتوزيع والطباعة ،عمان، الاردن.

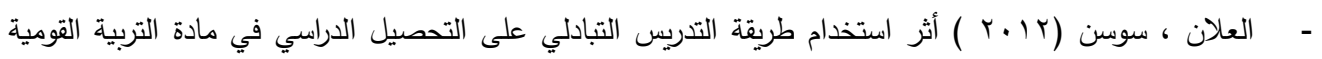

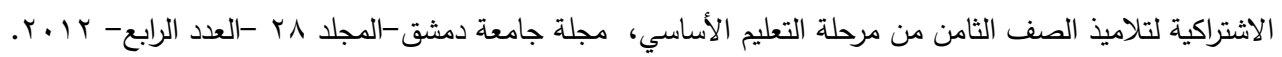

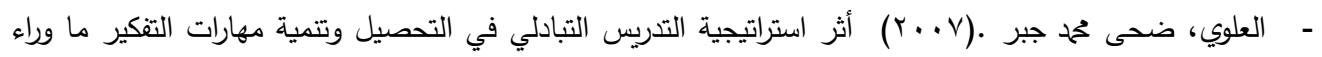

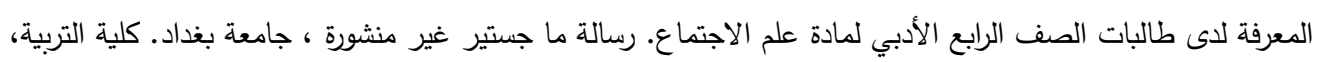
إبن رشد.

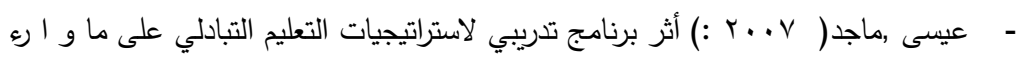

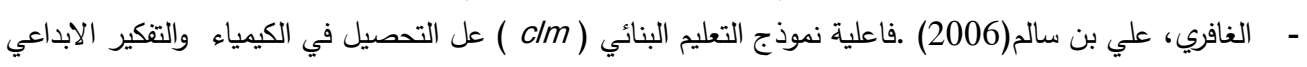

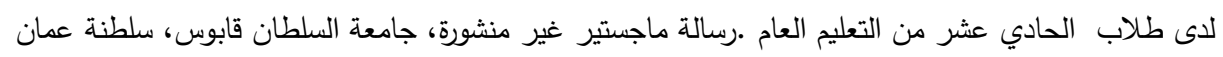

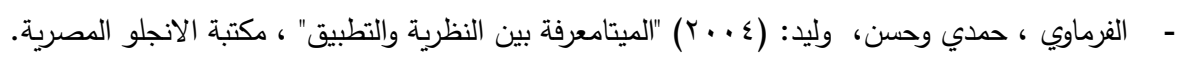

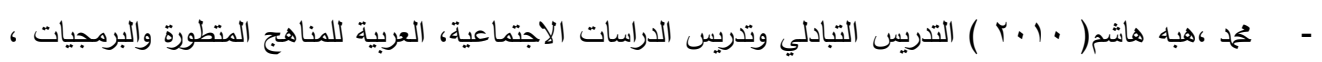

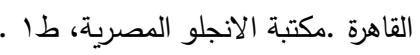

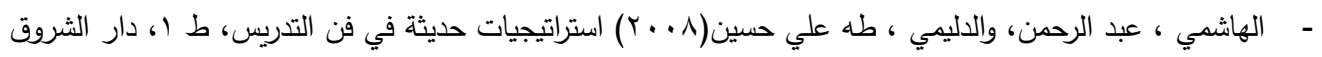
للنشر والتوزيع، عمان، الأردن.

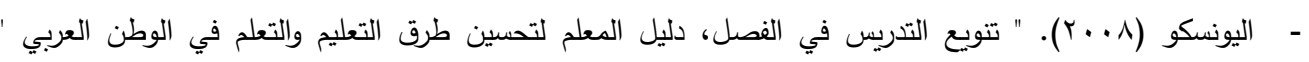
بيروت، مكتب اليونسكو الإقليمي.

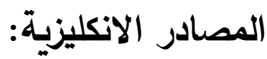

- $\quad$ Brown, A. \& Campione, j ( 1992 ).Students as Researchers (pp:49-57) Reston, VA: National Association of Secondary School 2000,and Teachers, In Keefe, W; Wilber (Eds.) . Teaching for Thinking

- Costa, A. \& Garmston, R. (2001). Cognitive Coaching: A Foundation for Renaissance Schools. Norwood, MA: Christopher Gordon Pubs. dyslexia and skills development centre. from: http: // www. Buffalostate. edu/org/cbir/index.asp. On: 4 May,

- Imel, S. (2000). Metacognitive Skills for Adult Learning. Retrieved

- Leather, C. and McLoughlin,D. (2001). Developing task specific metcognitive skills in literate dyslexic adult. London: Adult

- Mei, P. (2005). The Implication of Schema Theory، Metacognition and Graphic Organizers in English Reading Comprehension for Technical College Students in Taiwan. Thesis,Spalding University Principals. 